ISSN: 0514-7336 — ISSN electrónico: 2386-3943

DOI: https://doi.org/10.14201/zephyrus202188209234

\title{
LA ESCENA NAVAL DEL ABRIGO DE LAJA ALTA (JIMENA DE LA FRONTERA, CÁDIZ). UNA NUEVA PROPUESTA CRONOCULTURAL
}

\section{The Naval Scene of Laja Alta Shelter-Cave (Jimena de la Frontera, Cádiz). A New Chronocultural Proposal}

\author{
Ana María Gomar Barea \\ Gabinete Ayes SL. Avda. Virgen de la Palma, 1, portal 2, entreplanta. 11204 Algeciras (Cádiz). Correo-e: \\ agomarbarea@academiaayes.es. ID ORCID: https://orcid.org/0000-0002-3242-5842
}

Recepción: 6/05/2021; Revisión: 7/09/2021; Aceptación: 12/11/2021

Resumen: Presentamos una revisión de los motivos barquiformes del abrigo de Laja Alta, en Jimena de la Frontera, Cádiz, aportando una nueva hipótesis sobre su posible filiación a tiempos históricos. Desde el descubrimiento de este enclave, la razón de la existencia y la cronología de las embarcaciones que forman parte de sus paneles pictóricos han resultado aspectos controvertidos. Esta discusión se debe, en parte, a que estos barquiformes se alejan notablemente de la facies del Arte Rupestre Esquemático en el que, hasta ahora, se han venido incluyendo. Pensamos que la escena naval responde a una acción gráfica que se ajusta a la concepción de los modos de representación del fenómeno del grafito histórico. Nos sumamos al prolífico debate sobre la adscripción cronocultural de los navíos aportando nuevos datos, obtenidos de una propuesta metodológica que plantea el análisis de los barquiformes aislándolos del espacio físico en el que se ubican y de la técnica con la que se ejecutaron, circunstancias que, hasta ahora, han condicionado la mayoría de las reflexiones realizadas sobre ellos.

Palabras clave: Prehistoria; Baja Edad Media; extremo meridional peninsular; Campo de Gibraltar; motivos navales rupestres; grafito histórico; tecnología naval.

AвSTRACT: We present a review of the boat-shaped motifs of the Laja Alta shelter-cave, in Jimena de la Frontera, Cádiz, providing a new hypothesis on its possible affiliation to historical age. Since the discovery of this enclave, the reason for the existence and the chronology of the boats that form part of its pictorial panels have been controversial. This discussion is due, in part, to the fact that these ships are notably distant from the facies of the Schematic Rock Art in which, until now, they have been included. We think that the naval scene responds to a graphic action that fits the conception of the modes of representation of the historical graphite phenomenon. We join the prolific debate on the chrono-cultural ascription of the ships by contributing new data, obtained from a methodological proposal that proposes the analysis of the boats, isolating them from the physical space in which they are located and from the technique with which they were executed, circumstances that, until now, have conditioned most of the reflections made on them.

Key words: Prehistory; Middle Ages; Southern Peninsular Tip; Campo de Gibraltar; Rock Naval Motifs; Historical Graffiti; Naval Technology. 


\section{Introducción ${ }^{1}$}

El yacimiento de Laja Alta (Fig. 1) es uno de los enclaves que cuenta con más publicaciones y referencias, tanto en ámbito local como en el nacional e internacional, realizadas por investigadores de las manifestaciones gráficas prehistóricas, pero también por especialistas en la historia de la navegación. Desde su descubrimiento (Barroso, 1978), a lo largo de más de cuatro décadas de estudio, se han desarrollado múltiples trabajos que ofrecen conclusiones contradictorias sobre la existencia y la cronología de los navíos y la escena que conforman. El panel pictórico muestra una realidad compleja, con una composición de naturaleza heterogénea, a lo que se añade lo inusual de las representaciones de embarcacio-

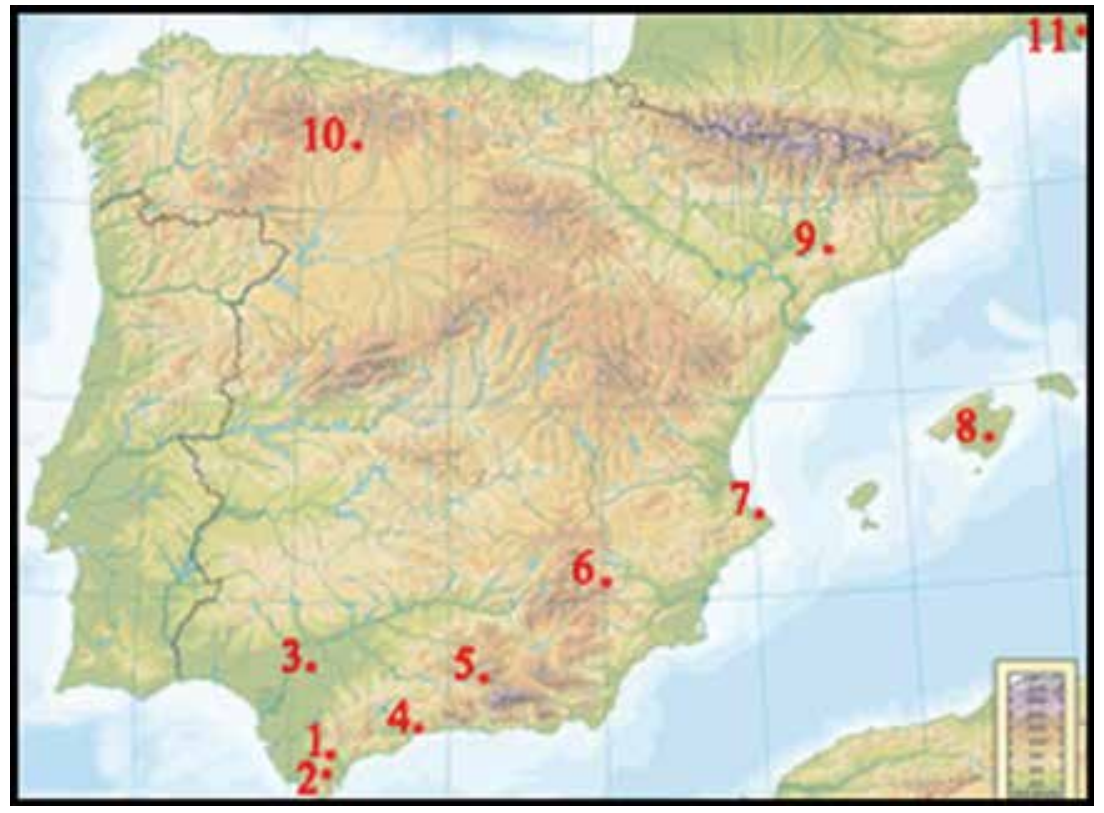

FIG. 1. Localización del abrigo de Laja Alta y otros lugares peninsulares citados en el texto: 1) abrigo de Laja Alta, Jimena de la Frontera, Cádiz; 2) abrigo de los Alisos o del Caballo, Los Barrios, Cádiz; 3) castillo de Alcalá de Guadaira, Sevilla; 4) alcazaba de Málaga; 5) murallas del Albaicin, Granada; 6) cueva del Esquilo, Moratalla, Murcia; 7) castillo de Denia, Alicante; 8) castillo de Santueri, Mallorca; 9) monasterio de Santa Maria del Poblet, Tarragona; 10) cuevas de Villacontilde, Villasabariego, León; 11) abadía de Montmajour, Arlés. nes en el conjunto de manifestaciones gráficas de las sociedades prehistóricas, donde han sido contextualizadas. La inmensa mayoría de los trabajos publicados hasta ahora lo sitúan en época prehistórica o protohistórica, a excepción de las propuestas de Aubert (1999) y de Sassoon (1993), que sugieren una cronología fenicio-cartaginesa o romana -ss. I-III d. C. - respectivamente. Posiblemente, fue el mismo contexto geográfico y físico lo que hizo que, desde un principio, el abrigo quedara enmarcado conceptualmente en la categoría de yacimiento prehistórico, sesgando así las hipótesis de partida, además de vedar las incursiones de especialistas en otros periodos. De esta manera, nos encontramos ante las dos principales tesis reflejadas en la historiografía sobre la investigación del abrigo y que explican la naturaleza de estos barcos: el encuentro entre indígenas y colonos orientales, en reflejo

1 La autora de este trabajo forma parte del Grupo de Investigación PAIDI HUM-812 de la Univ. de Cádiz. del paradigma histórico de finales del siglo pasado; y los postulados que otorgan un origen tartésicoturdetano o de aborígenes íberos, defendidos en las publicaciones de este siglo. Pensamos que la disposición de la escena, el detalle de su elaboración, el uso de la perspectiva o el dinamismo que presentan las naves de Laja Alta no guardan afinidad con las diferentes facies del arte rupestre prehistórico peninsular. Esto nos motivó para abordar un estudio que intentara proporcionar una nueva explicación a las contradicciones que presentaba el abrigo y, a la vez, que justificara la presencia de la escena naval en esta ubicación. La decisión de ampliar el ámbito cronológico objeto de estudio se asocia a otro hecho determinante: la recurrencia de la tipología de barquiforme en las manifestaciones gráficas de cronología medieval y moderna (Royo y Gómez, 2002: 64; Ozcáriz, 2008: 293). 


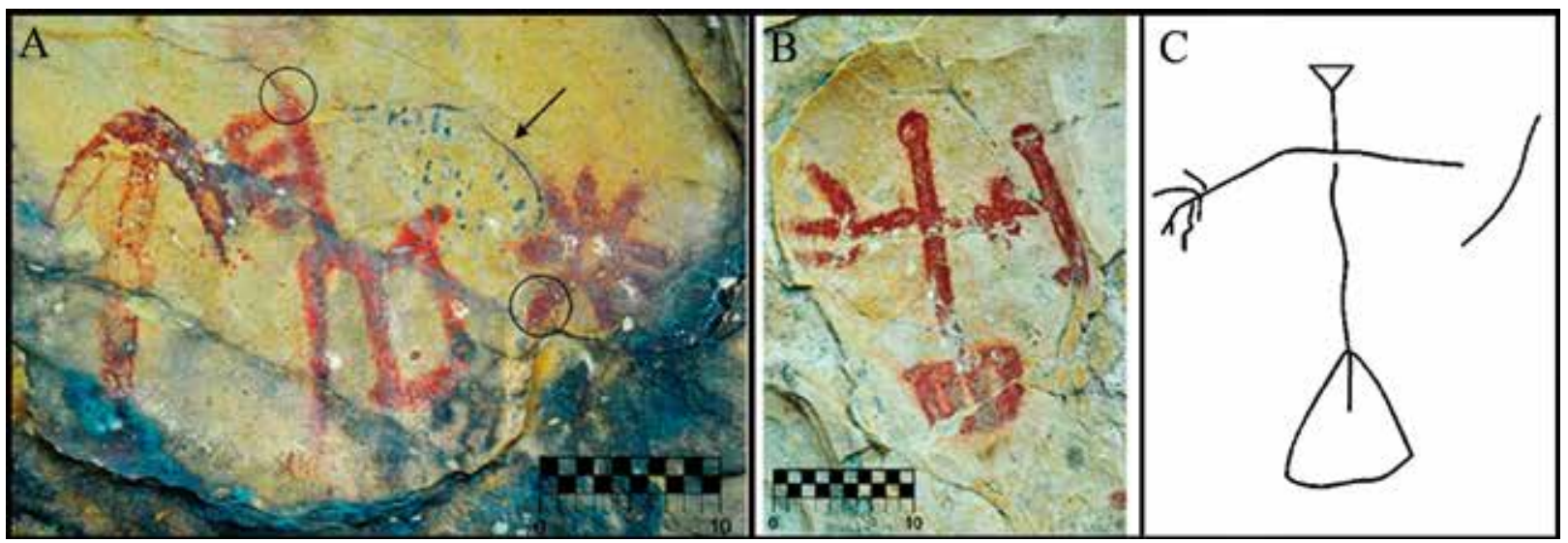

Fig. 2. Detalle de los motivos de Laja Alta: A) marcadas con círculos las continuidades de trazo en descamaciones; la flecha indica salpicaduras de pintura industrial en color negro. B) cruciforme con peana de Laja Alta. C) calco de grafito inciso cruciforme medieval de la cueva 2/I de Villacontilde, Villasabariego, León (según Jimeno, 2015: 406).

\section{Estado de la cuestión}

En general, el marco físico en el que se encuadra la escena naval de Laja Alta y la técnica de su ejecución han sido la base de las reflexiones teóricas en torno a su datación. Condicionados por este contexto, las comparaciones morfológicas de los primeros estudios acotaron la búsqueda de paralelos en naves, si no coetáneas, sí cercanas al ámbito cronológico del Arte Rupestre Esquemático -en adelante ARE-, relacionándolas, en un principio, con un ámbito precolonial no más allá del I milenio a. C., fecha muy posterior al final de la facies esquemática prehistórica (Acosta, 1984: 53). Múltiples trabajos intentaron establecer paralelos morfológicos con embarcaciones de tradición oriental, cuyo análisis partía de hallar similitudes con registros iconográficos, de los que se tomaron, aisladamente, distintos elementos navales tecnológicos o arquitectónicos. Este procedimiento derivó en la atribución de parecidos parciales a una amplia gama de embarcaciones, adscritas a diferentes contextos culturales del Mediterráneo en el I y II milenio a. C. (Corzo y Giles, 1980; Almagro, 1988; Aubert, 1999; Ruiz-Gálvez, 2005)². En diferentes trabajos se

2 También cf. Alvar, J.: La navegación prerromana en la Península Ibérica: colonizadores e indígenas. Tesis doctoral defendida en 1980 en la Univ. Complutense de Madrid; García Alfonso, E.: El impacto colonial fenicio arcaico en el rechazó la semejanza absoluta con naves fenicias $\mathrm{u}$ orientales, por la escasa concordancia morfológica, y se tuvieron muchas dificultades para establecer algunos paralelos iconográficos claros con barcos de otras civilizaciones como la egipcia, egea de la Edad del Bronce, minoica, griega, sarda o protohistórica itálica. Frente a la contrariedad de las comparaciones, surgió una nueva hipótesis basada en considerar a los navíos de Laja Alta como el resultado de una tecnología autóctona, fuera de cualquier influjo de civilizaciones orientales (Guerrero, 2008a y b; Alonso, 2011; Martín Goërg y Martín Arrazola, 2011, 2012; Vázquez, 2014, 2019; Martín Goërg et al., 2016; Morgado et al., 2018; Moyano, 2018) ${ }^{3}$. Esto implicaría retrasar significativamente la edad cronológica de estas embarcaciones, haciéndolas compatibles con las fechas que se le atribuyen al ARE. Recientemente, la datación directa de un motivo del abrigo -entre 3.938 y 3.649 a. C.-, quizá sobrestimada (Morgado et al., 2018: 258), y la

hinterland de Andalucia mediterránea (siglos VIII-VI a. C.). Tesis doctoral defendida en 2010 en la Univ. de Málaga; Bravo, S.: Dinámicas de control ideológico y territorial en el Estrecho de Gibraltar en épocas fenicia, púnica y romana. Tesis doctoral defendida en 2010 en la UNED.

3 Además, Vázquez, I.: La navegación precolonial en la Península Ibérica y sus relaciones con el Mediterráneo occidental. Tesis doctoral defendida en 2019 en la Univ. de Zaragoza. 
extrapolación de estas fechas al resto de figuras de Laja Alta por estudios espectrométricos dan un respaldo definitivo a esta última teoría apuntalando fechas del IV-III milenio a. C. en un intento de zanjar el tema. No obstante, la naturaleza de la composición de los paneles de Laja Alta presenta un alto grado de heterogeneidad, lo que reflejaría distintas fases de ejecución. Observamos la existencia de superposiciones, distintas tonalidades de pigmento, presencia de trazos de distinto grosor, variedad en las dimensiones de las figuras y muy diferentes estados de conservación, entre otras consideraciones. Resulta significativo que algunos motivos presenten una apariencia 'reciente', con un color abigarrado y de 'aspecto extraordinariamente fresco' (Mas, 2001: 171). Son figuras con una excelente conservación, cuyos trazos se sitúan en descamaciones sin sufrir deterioro en su continuidad. Además, son signos en una ubicación periférica, alineados en un eje horizontal, sobre los que se ven 'salpicaduras de pintura industrial' (Mas, 2001: 171) (Fig. 2A). Otro ejemplo a reseñar es el caso del cruciforme situado a la derecha de las anteriores figuras (Figs. 2в у 3). Este comparte semejanza con ejemplos de cruces con peana en iconografía histórica (Fig. 2c). Todos estos detalles delatan una escasa identidad técnica, de estilo y, posiblemente, cronológica entre sus motivos; además de explicar la poca uniformidad del conjunto, cuestión que no solo pueda atribuirse a repintes como apuntan otros autores. Otro aspecto a considerar es el hecho de que los barquiformes de Laja Alta no muestran sintonía respecto a la facies del ARE. Como hemos indicado, su disposición en escena, el insólito detallismo en alguna de estas representaciones, el uso de la perspectiva y lo excepcional de su temática son evidencias que los alejan de los restantes motivos del abrigo (Fig. 3). La minuciosidad en alguno de sus dibujos muestra tal gama de elementos técnicos que incluso los autores que defienden su adscripción al ARE han abordado su análisis descriptivo al detalle. Estos autores han llegado a pormenorizar un conjunto de elementos como aparejos, remos, timones, castillete de proa, mástiles únicos, mástiles bípedos, dobles arboladuras, tipos de velas, espolones, jarcias, obenques, estayes, aplustros, gallardetes, etc., una extensa lista de rasgos en la que se han incluido, además, los refuerzos internos de las cuadernas del casco (Barroso, 1980: 35). Esta eventualidad ha apremiado a algunos investigadores a tratar tal circunstancia en sus publicaciones y a ajustar, inevitablemente, sus tesis a dicha evidencia. La excepcionalidad de los barcos

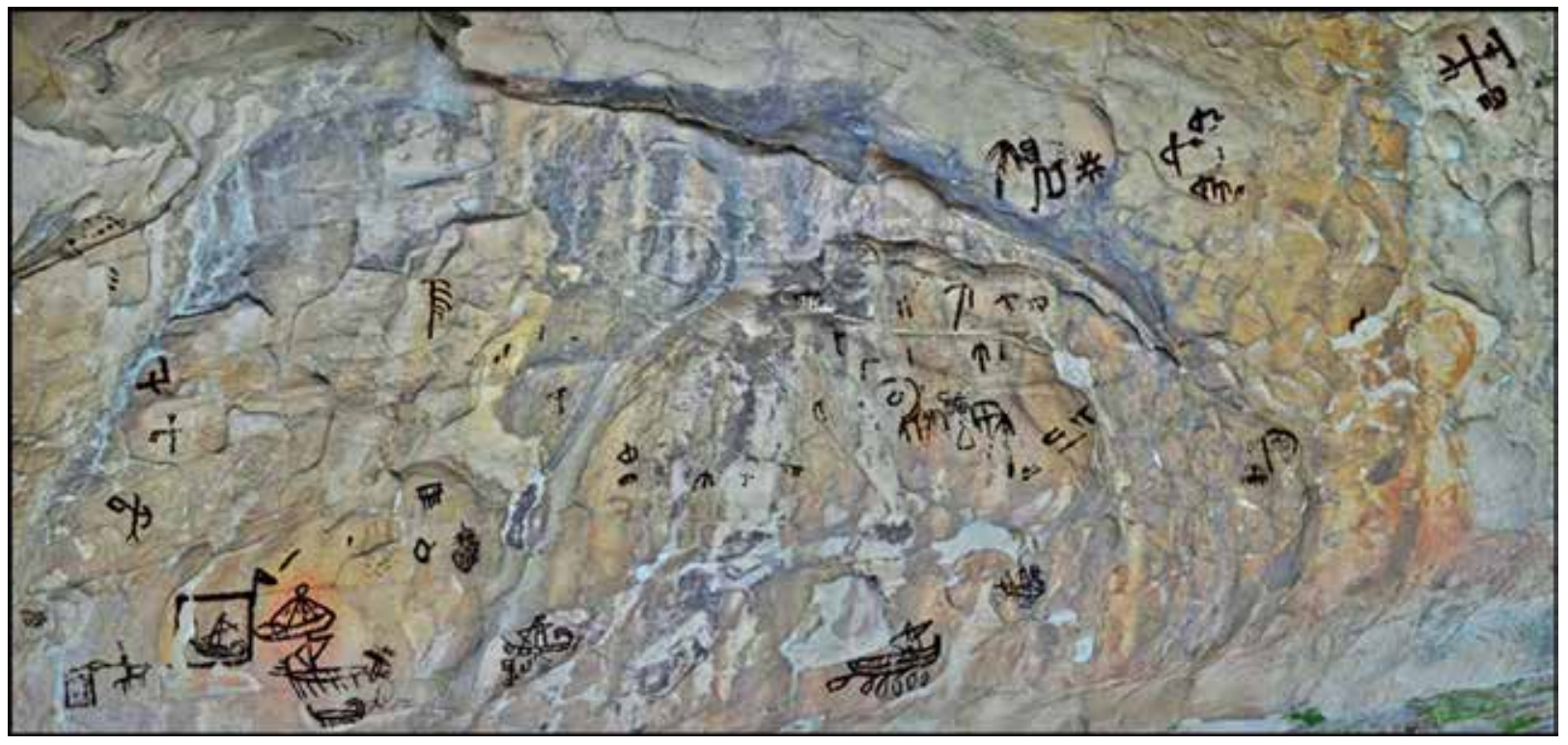

Fig. 3. Ortofoto de los paneles de Laja Alta a partir de restitución 3D y calco superpuesto. 
se ha justificado en algunos trabajos de forma insustancial, con argumentos que incluyen términos como impacto, asombro o estupefacción de una población indígena motivada a realizar unas naves relativamente perfectas (Barroso, 1978: 8; 1980: 40; Almagro, 1988: 398; 1995: 17) $)^{4}$. Otros auto-

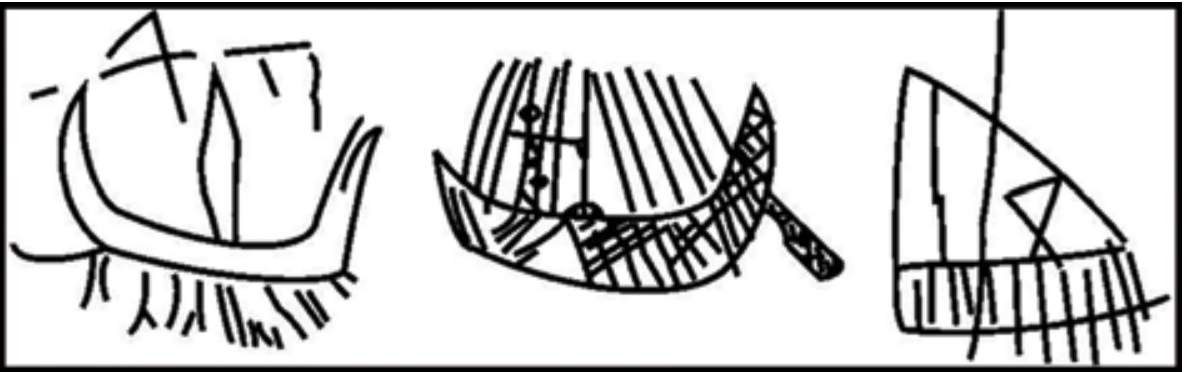

FIg. 4. Grabados en contexto histórico de barcos medievales de estilo esquemático en Pliska y Preslav, Bulgaria (https:/les.wikipedia.org/wiki/Armada_medieval_b\%C3\%BAlgara; acceso 18/01/2020). res, aun defendiendo cronologías prehistóricas, admiten el alejamiento de los modos de representación del ARE y afirman una naturaleza figurativa de los navíos, en la que no falta el uso de perspectiva (Guerrero, 2008a: 41; Martín Goërg y Martín Arrazola, 2011: 178; 2012: 19-20; Vázquez, 2019: 300, 301 y 303). En otras ocasiones se dictamina que las embarcaciones se representan con diseños muy esquemáticos, pero es posible ver rasgos que los sitúan en época prehistórica (Alonso, 2011: 113) o que son barcos técnicamente complejos con arquitectura arcaizante (Morgado et al., 2018: 256). Creemos que, en determinados casos, se ha confundido el término convencional de 'Arte Esquemático', adscrito a un concepto cronocultural de la Prehistoria, con la denominación de la técnica gráfica del esquematismo. Este último puede llegar a reducir la expresión de los elementos de un objeto a un esquema y se suele usar en épocas históricas, incluso en contexto rupestre (Fig. 4). Respecto a la temática, los motivos naviformes no son figuras recurrentes del corpus iconográfico que caracteriza el ARE de la provincia de Cádiz ni del paradigma del ARE peninsular. Después de haber documentado más de 250 enclaves rupestres en el Campo de Gibraltar y La Janda, en distintos proyectos autorizados por la Junta de Andalucía y dirigidos por M. Lazarich5

4 También García Alfonso, op. cit. n. 2, p. 350.

5 Proyectos vinculados con este tema en los que la autora ha colaborado son Vida y muerte en los entornos de la antigua laguna de La Janda durante la Prehistoria Reciente, financiado por el Plan de divulgación de la Ciencia y del Conocimiento de la Unidad de Cultura Científica y de cuestionamos la existencia de los motivos navales prehistóricos localizados en varios abrigos de la comarca por autores como Tooper y Topper (1975, 1988), Dams y Dams (1984) y Bergmann (1995). La mayoría de estos trabajos presentan calcos poco fidedignos (Fig. 5), figuras que han sido interpretadas como barcos sin serlo y que han servido como base a muchos investigadores para apoyar la tesis de la existencia de un microcontexto que justificaría la adscripción de los navíos de Laja Alta a fechas prehistóricas. La inexistencia de barcos en esos abrigos nos lleva a la siguiente conclusión: los motivos de Laja Alta quedarían aislados y sin referencia iconográfica prehistórica en su entorno geográfico, algo que los hace aún más insólitos. En alusión a las dataciones realizadas en el abrigo de Laja Alta por Morgado et al. (2018), de los resultados obtenidos mediante el análisis de espectrometría óptica de las

la Innovación (UCC + I), desarrollado en 2019-2020; Patrimonio arqueológico de la cuenca del río Barbate. Estudio de las necrópolis megaliticas y su vinculación con las manifestaciones rupestres en el entorno de la antigua laguna de La Janda (Benalup-Casas Viejas, Alcalá de los Gazules, Medina Sidonia, Vejer de la Frontera, Barbate y Tarifa), financiado por la Consejería de Cultura y Patrimonio Histórico (ref. DPPH/ATP Expt.A.01/19 1243), desarrollado en 2019-2020; Patrimonio arqueológico de la cuenca del río Barbate: las necrópolis megalíticas, Proyecto UCA PR2018-086, Programa de Impulso de la Actividad Investigadora de la Univ. de Cádiz, desarrollado en 2018-19; todos ellos han sido dirigidos por la Dra. M. Lazarich. Además, el proyecto dirigido por E. M. Briceño: Estudios de materiales "El ocre y sus aplicaciones en las manifestaciones culturales de la Prehistoria Reciente en la provincia de Cádiz”, financiado por la Junta de Andalucía, (DPPH-A-521/08), desarrollado en 2010-2011. 


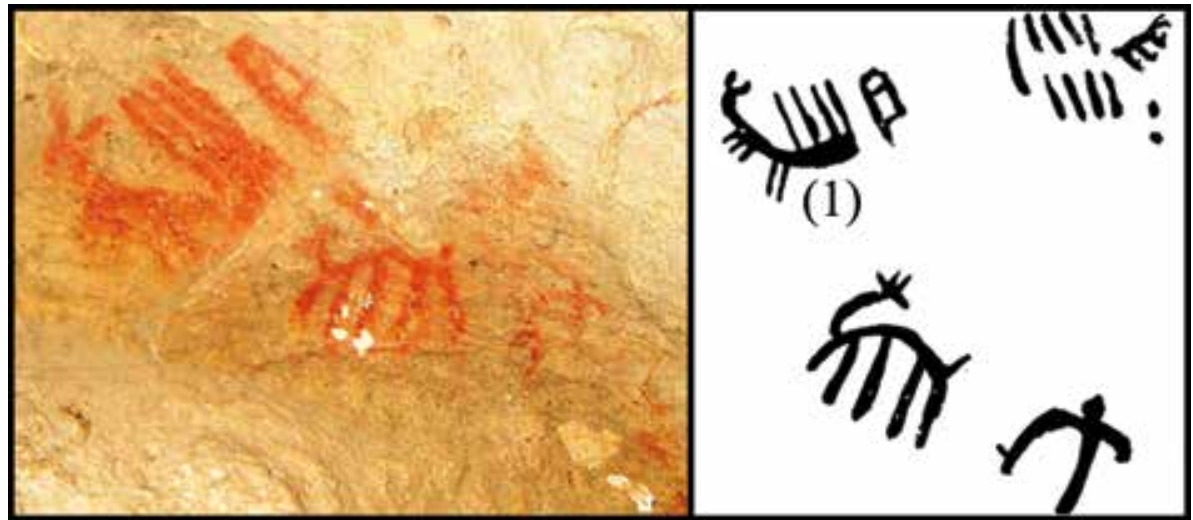

Fig. 5. Detalle de panel de la cueva de los Alisos o del Caballo: a izqda. fotografía tratada digitalmente; a dcha. calco con interpretación de una figura (1) de barco con proa toriomorfa (segun Topper, 1975: 27; Topper y Topper, 1988: 118). determinantes e inferir ciertas conclusiones a partir de ellos puede resultar poco sostenible (Mas, 2013).

\section{Metodología}

La propuesta metodológica que planteamos nace de la idea de no encasillar a priori los motivos de Laja Alta en una determinada etapa temporal y aislarlos embarcaciones, ídolos en rojo y resto de figuras esquemáticas en pigmento ocre, se concluye que todas estas figuras quedarían vinculadas, pues se realizaron con compuestos similares y se admite una sincronía en su ejecución, situándolas en torno al IV-III milenio a. C., fecha obtenida por datación directa $\mathrm{C}^{14}$ en un ídolo en pigmento negro superpuesto a una figura roja. Bajo estos preceptos nos es difícil explicar cómo determinadas descamaciones no han sufrido deterioro por el paso del tiempo, como evidencia la ejecución de trazos continuos en las mismas (Fig. 2A); circunstancia que observamos en algunos motivos navales (Fig. 6). Por otra parte, añadimos que los estudios de espectrometría no son del espacio físico en que se ubican. La dificultad del problema a resolver obligaba a desarrollar una estrategia metodológica que evitara el reduccionismo. La simplificación de un objeto en partes aprehensibles puede llevar aparejada cierta subjetividad, además de llevarnos a obviar detalles determinantes para la explicación de su existencia. Partimos de la idea holística de que el todo es siempre algo más complejo que la mera descripción de cada una de sus partes. Por tanto, la escena naval de Laja Alta debía ser abordada desde un enfoque que atendiera a la explicación de todos los sistemas involucrados en la concepción y creación del objeto y que, además, diera respuesta a su existencia en ese contexto físico,

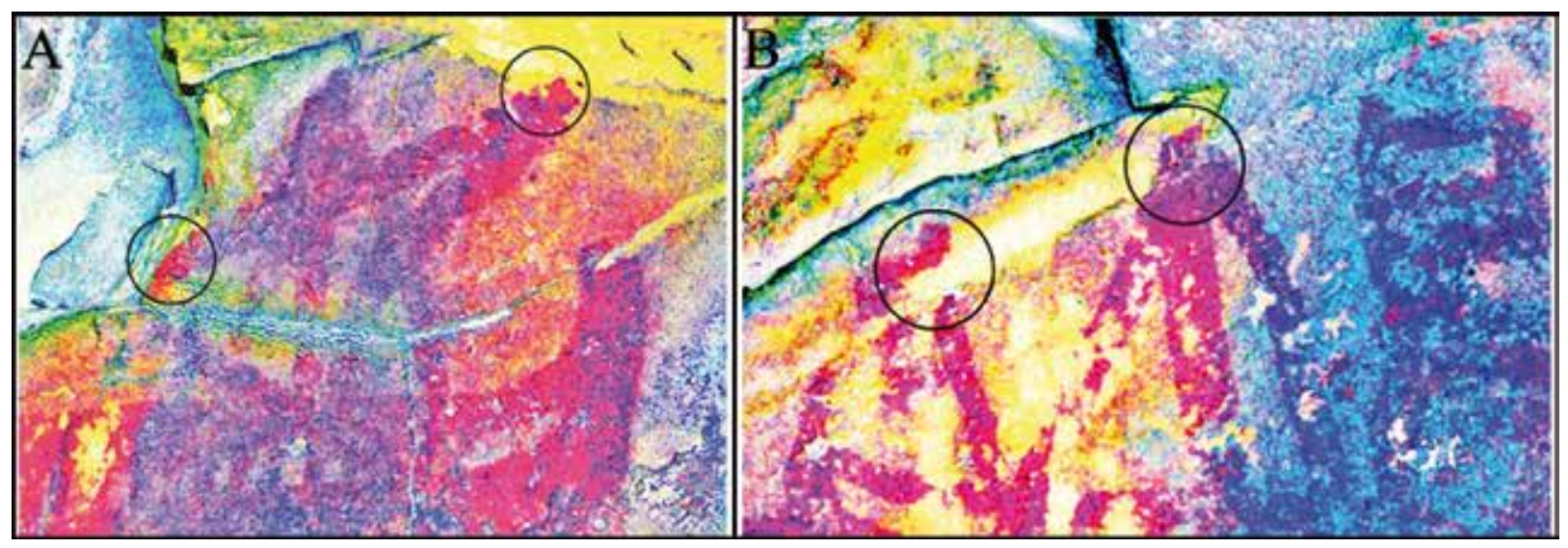

Fig. 6. Detalles de Laja Alta: A) barquiforme n. ${ }^{\circ}$; B) barquiforme $n .^{\circ}$ 7; marcado con círculos el pigmento que sobrepasa la linea de rotura del panel fosilizado. 


\section{Una nueva propuesta cronocultural}

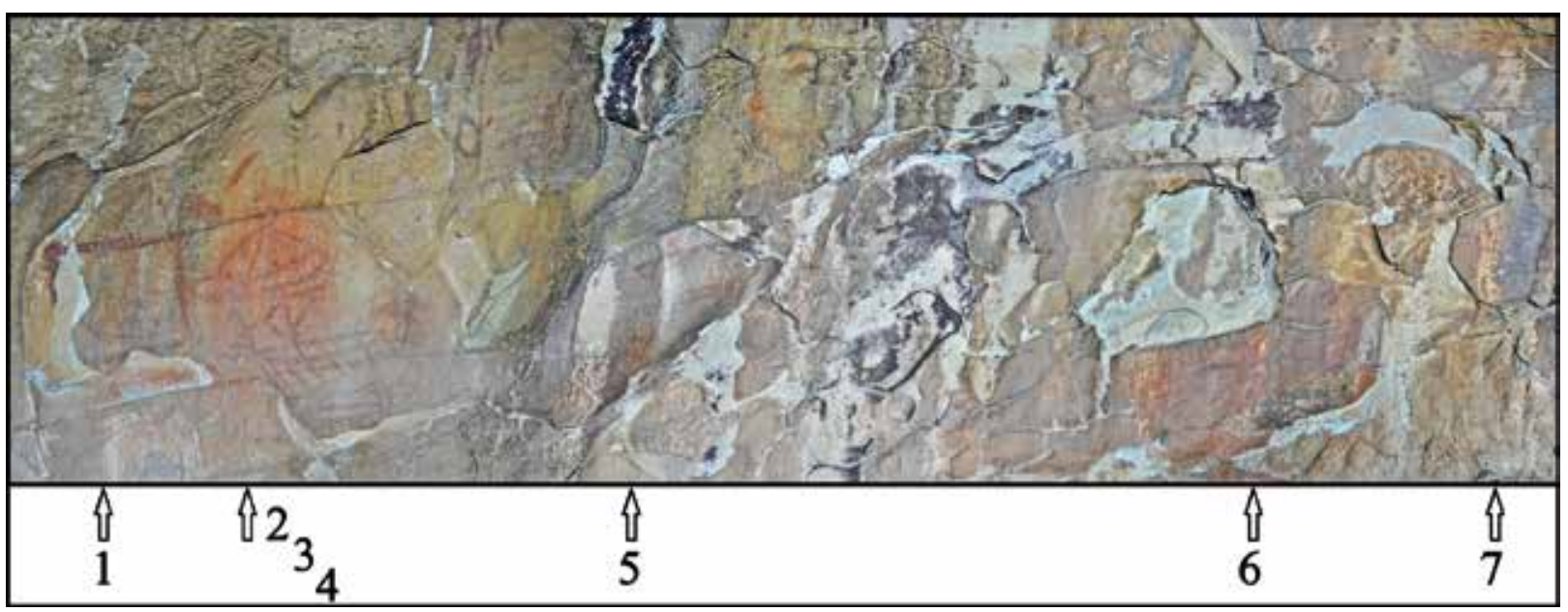

Fig. 7. Restitución 2D de la escena naval de Laja Alta y localización numerada de los navios.

técnico y tipológico. Decidimos, por tanto, obtener datos a partir de más de un sistema de información e integrar diversas perspectivas de investigación. En una primera etapa, obtuvimos unos registros digitales para abordar la confección de calcos y restituciones lo más detallados posible. Esta documentación se realizó hace ya más de una década ${ }^{6}$. El uso de una cámara réflex digital nos permitió obtener unas imágenes con un tamaño de 4288 x 2848 píxeles, profundidad 24 bits y resolución 300 ppp. Para la confección de las reproducciones digitales hemos usado técnicas actualizadas y habituales en el estudio del Arte Rupestre, que tienen como base los programas informáticos de diseño gráfico vectorial. El software ImageJ (D-Stretch) ha proporcionado, para cada una de las figuras, unos registros digitales con distintos tratamientos para el realce del pigmento. Las convergencias observadas en este conjunto de imágenes han servido de guía para la elaboración de cada uno de los calcos de las figuras, que han sido realizados a partir de la selección de una o varias fotografías digitales tratadas. Seleccionando puntos de semejanzas cromáticas, a partir de la herramienta de máscara de color -Corel Photo-Paint X8-, logramos cribar los píxeles que formarán parte del calco

6 Contamos con la autorización de la Delegación de Cultura de la Junta de Andalucía, dentro de un proyecto dirigido por la Dra. M. Lazarich, responsable del Grupo de Investigación PAIDI HUM-812 de la Univ. de Cádiz. final de la figura. Finalmente, estos se han coloreado en negro y el resto de puntos desechados forman el fondo del calco de tonalidad blanca. El calco definitivo de la figura naval publicada ha tenido varias fases de cotejo. La primera tiene como fundamento la realización de más de un calco, con fotografías distintas, para cada motivo naval y comparación de resultados. La segunda confrontación del calco se realiza con un conjunto de imágenes con diferentes tratamientos digitales del motivo, la última fase es la verificación in situ. Por otro lado, alguna de estas reproducciones de los barquiformes se ha logrado mediante la composición de varios calcos de distintas zonas de la figura. Previamente, se han realizado tratamientos digitales específicos para cada una de estas partes en la que se ha troceado el motivo. El objetivo es intentar contrastar al máximo las tonalidades ocres y facilitar los calcos. Por último, se ha ejecutado el montaje de estas zonas o porciones sobre una imagen escalada del navío. Para ello hemos recurrido al software Adobe Photoshop CS5, que permite una superposición y unión de varias imágenes por capas. La técnica aplicada se fundamenta en la poca uniformidad del pigmento que muestran algunas figuras debido a un deterioro irregular. Tal circunstancia hace que la aplicación de un único tratamiento uniforme a la fotografía digital no refleje todo su potencial. Las reproducciones que mostramos aportan nuevos detalles $y$ 
actualizan los publicados por otros autores; además, nos han reportado nuevos datos compatibles con las conclusiones de la investigación. Nos referimos, por ejemplo, a la continuidad de trazos sobre la ruptura de la roca fuera de los paneles fosilizados que, hasta ahora, habían pasado desapercibidos. Una vez obtenidos los calcos a la misma escala, se han incorporado a una reproducción digital 2D u ortofoto del panel (Fig. 3). Esta imagen nos proporciona una panorámica de la ordenación de los motivos dentro del abrigo. Para la escena naval y la disposición de los navíos hemos realizado otra restitución 2D más detallada (Fig. 7). Hemos recurrido al programa informático de edición de imágenes Adobe Photoshop CS5 para solapar y unir en distintas capas los registros fotográficos de los barcos más susceptibles de encajar unos con otros, teniendo como resultado final un panel rupestre digital bidimensional de las naves. Por otra parte, la ortofoto se ha obtenido a partir de una restitución 3D del abrigo. Esta reproducción tridimensional se ha realizado mediante el programa de procesamiento fotogramétrico Agisoft PhotoScan Professional -v. 1.4.5-. La segunda fase de este trabajo se basa en la comparativa formal, buscando paralelos en diferentes fuentes iconográficas, prehistóricas, protohistóricas e históricas y trabajando, simultáneamente, en dos niveles de análisis. Por una parte, partiendo de la idea del dibujo como medio de comunicación, nuestra investigación se encuadró en el marco metodológico del código gráfico para hallar semejanza en la representación. Esta fase de rastreo evidenció que los más claros paralelos en cuanto a sus rasgos estilísticos están acotados en la Baja Edad Media. En un segundo análisis, planteamos la identificación de los elementos de tecnología naval en las embarcaciones de Laja Alta, susceptibles de ser identificados y datados con claridad. Para aumentar la fiabilidad de los resultados, determinamos que tanto la comparación morfológico-estilística como la identificación de elementos de ingeniería naval debían converger hacia la misma hipótesis cronológica, de manera que fuera posible describir las embarcaciones de Laja Alta como una unidad de 'objeto construido', localizable en un tiempo y en un fenómeno cultural. Estos dos campos de análisis

Ediciones Universidad de Salamanca / 어요 han ido dialogando de forma constante en el transcurso de la investigación. No cabe duda de que la puesta en marcha de múltiples proyectos de estudio y catalogación de los conjuntos de grafito histórico en las últimas tres décadas, especialmente en el área levantina, nos ha permitido disponer de una extensa base iconográfica y, en consecuencia, la posibilidad de explorar nuevos encuadres cronológicos que hasta ahora no se habían podido afrontar.

En España, el desarrollo de las primeras aportaciones sobre grafito histórico se sitúa en el último tercio del s. xx en Cataluña, con el desarrollo de un proyecto de catalogación de grafitos medievales localizados en esa comunidad. Este trabajo generó una abundante producción científica y dio lugar a la celebración en 1983 de la I Mostra de grafits medievals de Catalunya. Todo este impulso investigador culmina en 1999 con la exposición Grafitis, 6000 anys de llenguatge marginal, que se acompañó con la publicación de un catálogo (Casanovas y Rovira, 1999). En la comunidad autónoma de Aragón dos hitos sitúan a los investigadores aragoneses en una posición de avanzadilla. Nos referimos a la celebración en 1982 del Colloque International de Glyptograhie de Saragosse, primer congreso de la institución del CIRG celebrado en España, en el que se aportaron monografías sobre estudios regionales (vv. AA., 1986). A finales de los años 80 del pasado siglo encontramos en la zona levantina las primeras referencias a grabados históricos. Estas atribuciones cronológicas se hacen tímidamente y en el marco de unos estudios de arte rupestre en la zona de Castellón (Viñas y Sarriá, 1981), Valencia (Hernández et al., 1986) y Alicante (Hernández et al., 1988). En Alicante sobresale el trabajo de un equipo hispano-francés de investigadores, que realiza los calcos de los grafitos del Castillo de Denia, cuyo resultado se publica en lo que se considera la primera monografía sobre grafitos en el ámbito valenciano (Bazzana et al., 1984). En Alicante, la labor investigadora desemboca en la celebración de una exposición monográfica sobre grafitos históricos en 2009, denominada Graffiti, arte espontáneo en Alicante. El éxito de las investigaciones se materializa en sucesivas jornadas y congresos en España, en los que

Zephyrus, LXXXVIII, julio-diciembre 2021, 209-234 
se comienzan a debatir los diferentes problemas y perspectivas metodológicas que planteaba el estudio de estas manifestaciones. Surge así la celebración del I Congrés Internacional de Gravats Rupestres i Murals en la ciudad de Lérida en 1992. Primer congreso en el que investigadores especialistas en distintos ámbitos cronológicos se dan cita bajo una denominación, esta engloba tanto las manifestaciones prehistóricas como históricas.

En referencia a las miniaturas de barcos presentadas en este trabajo que muestran similitudes a los navíos en Laja Alta, han sido útiles los manuscritos de códices comprendidos entre los ss. XII y XV. Respecto al estudio de los elementos tecnológicos navales, hemos contado con un corpus de trabajos sobre historiografía de tecnología naval enfocados desde diferentes disciplinas como la arqueología, la historia, los estudios náuticos o ciencias auxiliares como la iconografía o la filología. Circunstancia que ha facilitado esta labor, logrando acotar con cierta precisión, o al menos con unas fechas post quem, la cronología de algunos elementos técnicos que hemos apreciado en los navíos de Laja Alta. La obra de Pryor y Jeffreys (2006) y el estudio de Fondevila ${ }^{7}$ en el ámbito castellano han constituido las fuentes de información más recurrentes para nuestro estudio de los elementos de tecnología naval. En síntesis, mediante esta metodología hemos abordado una problemática que es común a muchos enclaves rupestres prehistóricos, en los que se documentan diferentes fases de ejecución y tipologías insólitas o con una menor frecuencia en el arte prehistórico. Para el estudio de las naves de Laja Alta, hemos reunido datos de más de un sistema de información. Dos de ellos nos aportan conclusiones coincidentes en cuanto a permitir una acotación de fechas para los navíos y escena -paralelos iconográficos y tecnología naval identificada-; el tercero nos ha reportado datos más compatibles con fechas históricas que prehistóricas -imágenes de detalle con trazos fuera de costras fosilizadas-. Lamentablemente, los

7 Fondevila, P. L.: Evolución y análisis de las galeras de los Reinos peninsulares (siglos XII-XVIII). Construcción, dotación, armamento, aparejos y táctica. Tesis doctoral defendida en 2018 en la Univ. de Murcia.

Ediciones Universidad de Salamanca / @థ@्ब motivos de la escena naval no se prestan a la aplicación de otras técnicas de contrastada eficacia, como pruebas radiométricas del isotopo $\mathrm{C}^{14} \mathrm{o}$ análisis de pátinas de oxalatos.

\section{Análisis de la tecnología naval y paralelos iconográficos}

Para desarrollar este análisis hemos numerado los barquiformes de Laja Alta desde el n. ${ }^{\circ} 1$ al 7 siguiendo un orden de izquierda a derecha y de arriba hacia abajo (Fig. 7). El conjunto de los navíos de Laja Alta muestra tamaños distintos y se pueden agrupar en relación con sus dimensiones: así, los hay que superan los $18 \mathrm{~cm}-\mathrm{n} .^{\text {os }} 2,3,5$ y $6-$ y los que no los alcanzan $-n .^{\text {os }} 1,4$ y 7 -. Como consideración previa, las embarcaciones de Laja Alta, a pesar de las descamaciones y fracturas del soporte, están casi completas. No hay que lamentar pérdida de detalles por desprendimiento de panel, a excepción de una pequeña descamación en la proa de la embarcación n. ${ }^{\circ} 4$, que podría haber afectado a alguna particularidad de la nave; y el desprendimiento de soporte en el signo geométrico que enmarca al barco n. ${ }^{\circ} 1$, que en este caso sí estamos convencidos de que afecta a su proa. Pensamos que los paneles fosilizados del abrigo en el momento en que se pintaron las naves tenían mucha similitud con la configuración que contemplamos en la actualidad. Esto explicaría la llamativa disposición de las embarcaciones n. ${ }^{\text {os }} 6$ y 7 , que se amoldan a la morfología de la costra existente, la cual marca los límites de estos barcos y explica el gran dimorfismo que hay entre ellos (Fig. 8). En el caso de la embarcación n. ${ }^{\circ} 6$, el mástil y el aparejo han sido ejecutados en la única posición posible, donde la costra alcanza su máxima altura. Este ajuste se puede justificar por la presencia de pigmento que dibuja la entena de la vela, que queda por fuera de los límites del panel fosilizado (Fig. 6A). Todas estas continuidades de trazos nos advierten del escaso deterioro del panel después de haber sido dibujado, por lo que son indicios de una fecha de ejecución más reciente que la prehistórica. Para la embarcación n. ${ }^{\circ} 7$ se puede dictaminar lo mismo, 


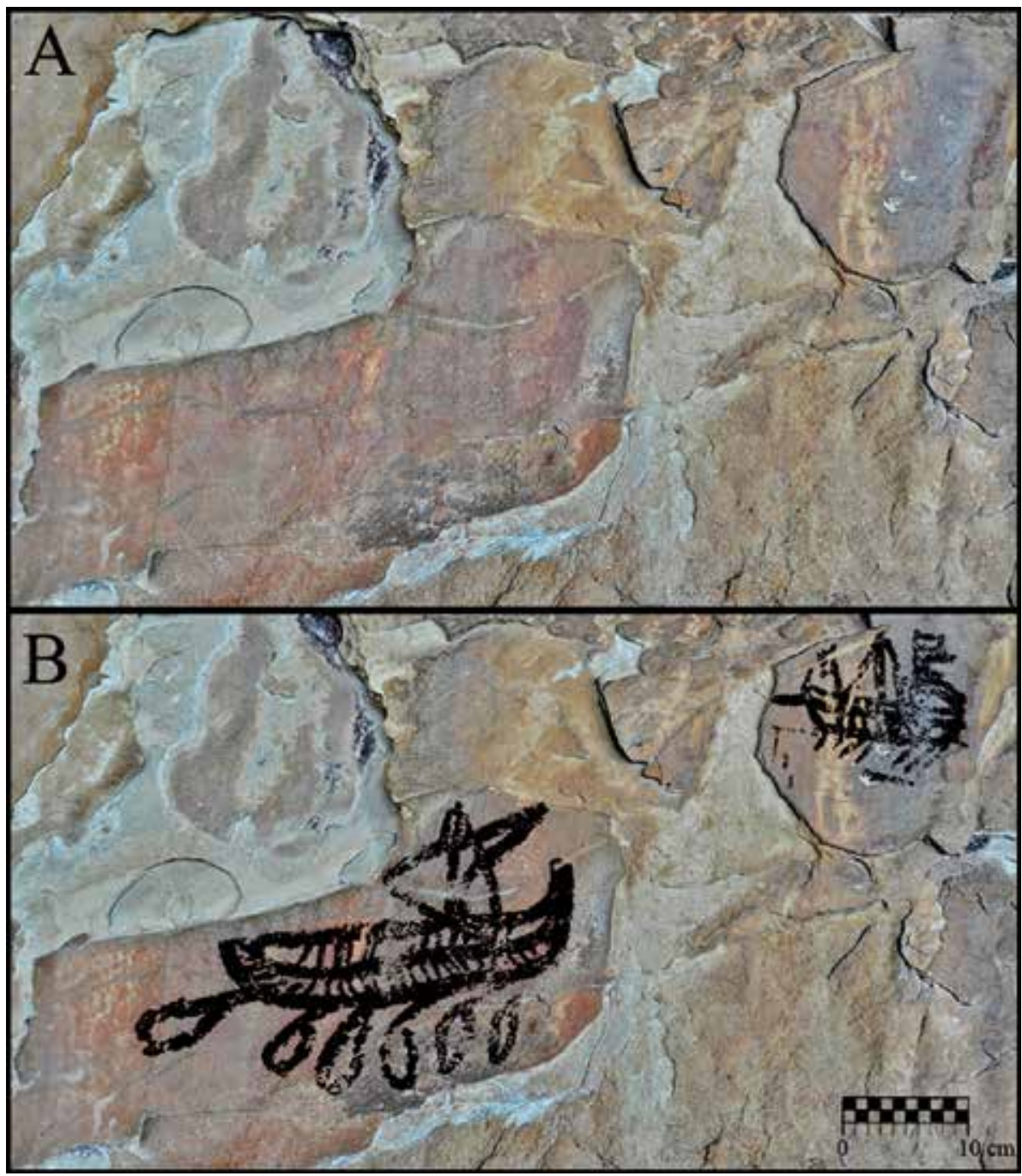

Fig. 8. Panel de Laja Alta: A) barquiformes $n{ }^{o s} 6$ y $7 ;$ B) misma área con calcos superpuestos a las costras fosilizadas.

queda embutida en la capa fósil y es posible atisbar pigmento en zonas de fractura y desprendimiento de costra (Fig. 6в). La escena muestra linealidad horizontal en su composición, no existiendo superposiciones y grandes distancias en un hipotético eje vertical. Respecto a la ejecución gráfica, en las embarcaciones $n .{ }^{\text {os }} 1$ y 6 se aprecia un intento de representación axonométrica en el dibujo de los cascos. Se hace visible la cubierta procurando un tipo de proyección, donde da la sensación de que el objeto se ha girado ligeramente a lo largo de un eje con relación al plano de proyección, lo que sugiere un

Ediciones Universidad de Salamanca / 어요 intento de dotar a las figuras de una tridimensionalidad. Respecto al análisis de la identificación de elementos tecnológicos, lo que más caracteriza a una nave, además de la morfología del casco, son aquellos elementos presentes en la denominada obra muerta -ubicados por encima de la línea de flotación-. Nos referimos sobre todo a elementos de propulsión y gobierno de las embarcaciones, apreciables en las representaciones iconográficas. Hemos analizado la manera de dibujar las velas, aparejos, morfología de la proa, popa, casco y uso de la perspectiva que muestran algunos navíos de Laja Alta. Las peculiaridades observadas en las naves de Laja Alta se ajustan a las características de las galeras del s. XIII: un solo árbol con calcés Modelo II y vela latina, alas recurvadas, popa más elevada que la proa, émbolo cónico que más tarde -en el s. XIV- dará origen a un espolón -las galeras más pequeñas no llevan émbolo- y un único orden de remos ${ }^{8}$. Pero observamos elementos navales que nos sitúan alguna de ellas en el s. XIV (triple espolón), e incluso otros que son más típicos de siglos anteriores al XIII, como los aplustres -adornos en popa-. Podemos ofrecer una explicación a esta disyuntiva por la escasa normalización en la construcción de las galeras durante la Edad Media, normalización que no se producirá hasta el

8 Fondevila, op cit. n. 6: 114. 


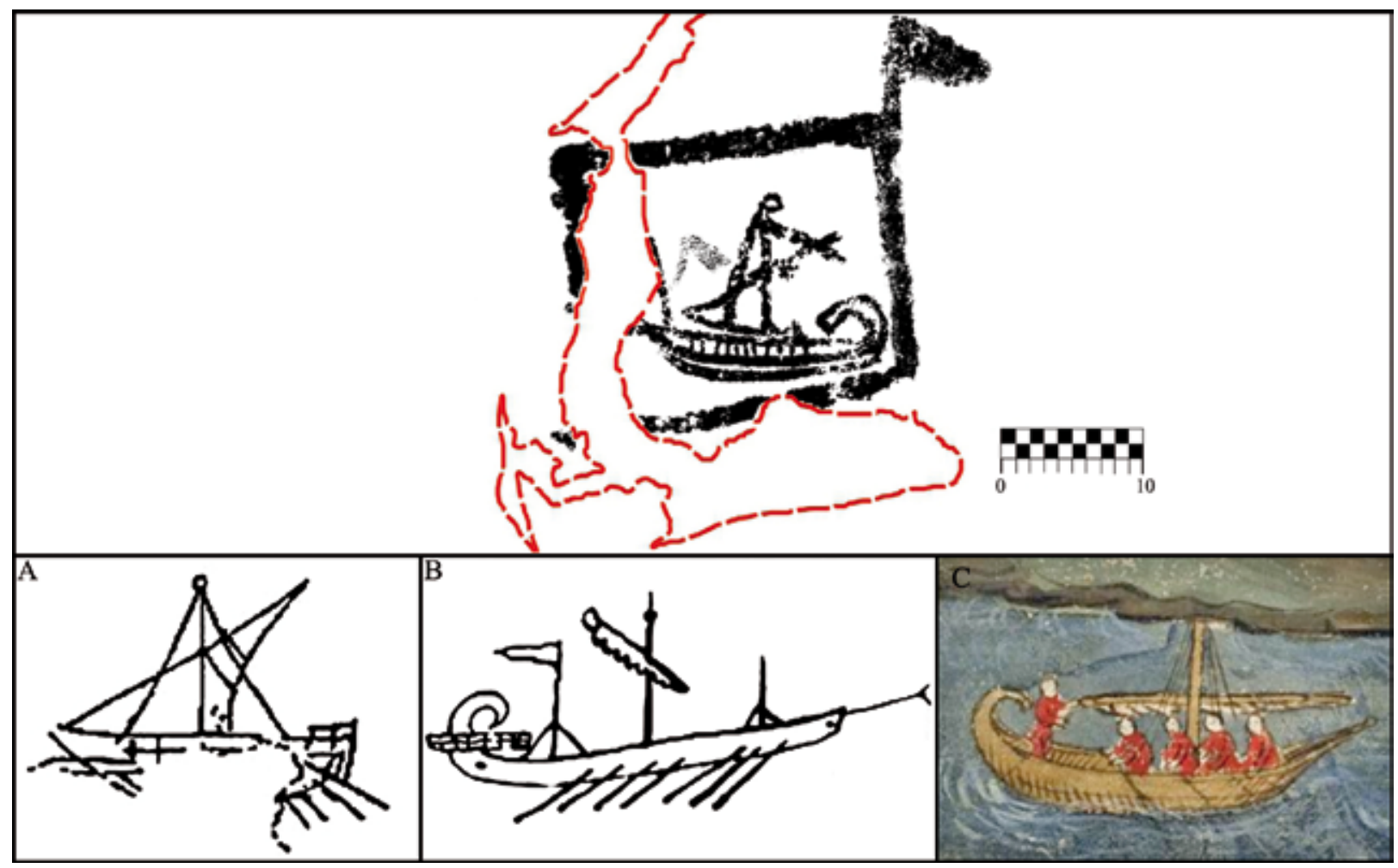

Fig. 9. Calco del barquiforme n. ${ }^{\circ} 1$ de Laja Alta y posibles paralelos: A) calco de una fusta grabada en la muralla de Albaicin en el s. XIV (según Casado, 2003: 539); B) calco del grafito de una galera del monasterio de Moni Vlastadon, en Tesalónica, del s. XIV (según Pryor y Jeffreys, 2006: 416); c) embarcación en una miniatura del Códice de San Pedro, folio 19v., del s. XV (seguin https://digital.blb-karlsruhe.delblbhs/content/pageview/3853545; acceso 18/07/2018).

s. XVIII ${ }^{9}$. Pasamos a analizar los barcos tomando como criterio de organización la existencia o no de velas. En el caso de los barquiformes que portan velas, los hemos clasificado en función de la similitud en el diseño del velamen que muestran entre sí. Las naves $n .{ }^{\text {os }} 1$, 3, 5 y 6 portan velas desplegadas, en otras dos $-\mathrm{n}$. $^{\text {os }} 2$ y 7 - creemos observar solo un mástil y cabos, finalmente en la embarcación n. ${ }^{\circ} 4$ no se dibujaron el mástil ni el velamen.

\subsection{Barquiforme.$^{\circ} 1$}

La embarcación n. ${ }^{\circ} 1$ de Laja Alta se encuentra inscrita en un signo de morfología rectangular. Este recuadro no aporta información sustancial en nuestra búsqueda de paralelos e identificación de los

9 Fondevila, op cit. n. 6: 118. elementos de tecnología naval de los barcos (Fig. 9). Entre los autores que han dado su interpretación sobre esta figura geométrica existe cierto consenso, catalogándolo como una estructura arquitectónica de tipo puerto o fondeadero, según Barroso (1980: 37-38); astillero y barco en estado de construcción, según Topper y Topper (1988: 235); puerto fenicio o cothon según Aubert (1999), Broodbank (2013: 496) y Rey (2014: 378-379); cothon o pequeño fondeadero artificial con banderola de señalización o indicador de puerto, según Guerrero (2008a: 45, 2009: 172), $\operatorname{Sintac}^{10}$ y Vázquez (2019: 135); corral de pesca, según Martín Goërg y Martín Arrazola (2011: 176; 2012: 20), o representación abstracta de una estructura, según Moyano (2018: 45). Otros

10 Sintac, S.: La navegación mediterránea en la Antigüedad. Trabajo de Fin de Grado defendido en 2014 en la Univ. de Zaragoza. 
investigadores (Corzo y Giles, 1980: 29) han creído identificar la representación iconográfica de lugares cercanos, como el puerto de Carteya o la propia bahía de Algeciras. Por último, existe una teoría discordante respecto a las anteriores (Morgado et al., 2018: 256), que propone que estas representaciones rectangulares son signos de carácter alegórico, por lo que no deben interpretarse como la representación fidedigna de algo real. Centrándonos en el barco, este se presenta en perspectiva axonométrica que hace visible la cubierta. Distinguimos un mástil coronado con un signo circular en su extremo, una vela latina, casco de bajo calado y popa curvada. Parece que de la proa sobresale un trazo alineado que continúa paralelo a la misma y que podría ser interpretado como un émbolo, pero el deterioro del soporte por descamación nos impide asegurarlo. Émbolo, que no espolón, para diferenciarlo del que portarían los barcos clásicos de guerra fenicios, griegos y romanos, por debajo de la línea de flotación -ariete-. Por el contrario, las galeras medievales mantendrán un elemento parecido por encima de esa línea. Sobre los demás trazos que se sitúan en la popa del barco no hacemos interpretación, aunque uno de ellos nos recuerda la forma de un banderín. La representación del aparejo simula una vela latina desplegada, se hace a base de triángulos que se disponen solapadamente sobre un eje central que representa un mástil, a semejanza del paralelo en la
Fig. 9A. Observemos el mismo remate que corona el mástil de esta nave de Laja Alta en los paralelos de la Fig. 9A-B. Identificamos su morfología circular o punto grueso como una roldana o polea, bien representados en las naves de la Baja Edad Media (Fig. 10), y cuya función es alzar o arriar la verga de la vela latina (Fig. 10A). Esta pieza de carácter añadido, pues no se talla en el mástil, tuvo una evolución documentada y clasificada en tres tipologías. La representada en Laja Alta y sus paralelos corresponde a una segunda evolución, situada desde finales del $s$. XI hasta el s. XIV, y conocida como calcés Tipo II. Se conformaba en una polea de mayor diámetro que el mástil a diferencia de su antecesora calcés Tipo I -de los ss. VI-XI-. El aparejo latino que observamos se asocia con los avances técnicos en la construcción de los primeros dromones bizantinos. Es en el s. VI cuando se producen estos cambios radicales en las características de construcción de las galeras de guerra: la vela latina definitivamente reemplaza a la vela cuadrada y los espolones reemplazan a los arietes -espolón por debajo de la línea de flotación- (Pryor y Jeffreys, 2006: 446). La primera referencia textual de este tipo de vela es coincidente con esta fecha. Se encuentra en el libro ir de la Vida de San Cesáreo de Arlés escrita entre 542 y 549 d. C. Para ciertos autores existen evidencias que sitúan el origen de la vela latina en siglos anteriores, siendo datado en el ámbito del Mediterráneo en épocas precristianas

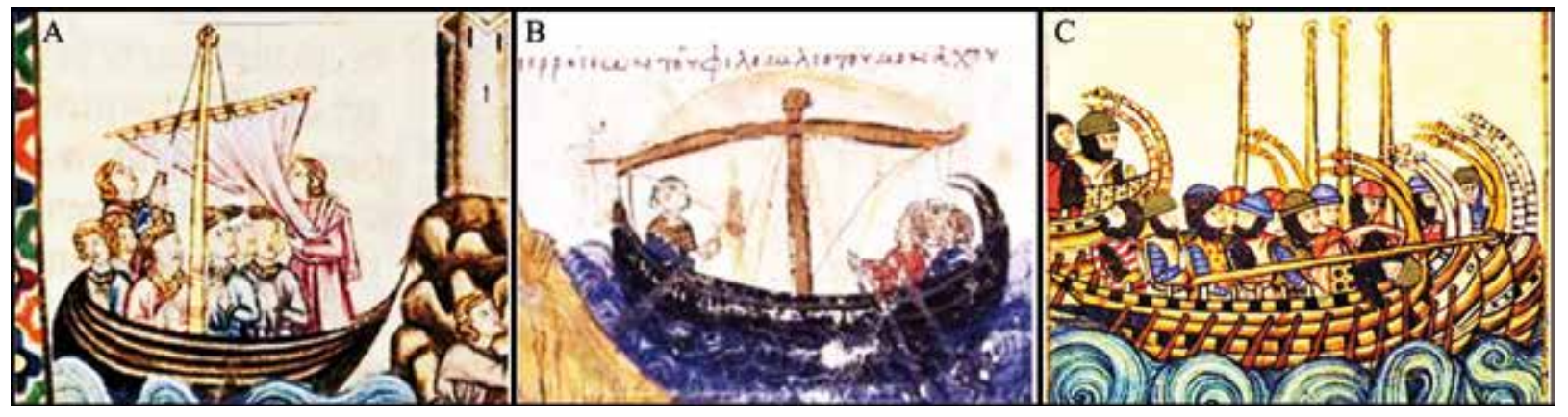

FIG. 10. Representaciones de embarcaciones medievales: A) batel con vela latina del s. XIII, en la que se advierte calcés de Tipo II y su función (según Cantigas de Alfonso X, n. ${ }^{\circ}$ XXXIII del Códice del Escorial, Ms. T-I-1, folio 48r.); B) nave de la familia de las galeras del s. XII, con calcés de Tipo II, con representación triangular de vela latina, proa alta y popa con aletas (según el Codex Graecus Matritensis Ioannis Skillitzes, Mr VITR/26/2, folio 15); C) galeras cristianas del s. XIII, con calcés de Tipo II, émbolo en proa y aletas curvadas en popa, en primer plano galera con mástil abatido (Cántigas de Alfonso X, $n .^{o}$ XXXV del Códice de El Escorial, Ms. T-I-1, folio 53r.). 
(Casson, 1971: 49-51). En consecuencia, proponemos el s. vi como referencia cronológica de la estandarización de este tipo de velamen en el Mediterráneo. Volviendo a la nave, la popa revirada tiene claros referentes en época medieval como muestran los paralelos в y c de la Fig. 9. Existen otras formas de popa en los paralelos encontrados, algunas de ellas conformadas a base de dos apéndices curvados y elevados hacia el interior. Ingenio que se observa en otros barquiformes de Laja Alta, y que son un atributo común en galeras del ámbito mediterráneo (Fig. 10B y c) hasta el s. XIV, conocidos con el nombre de 'aletas'. El paralelo de la Fig. 9 c muestra similitudes no solo en el casco, en la popa curvada, un solo mástil y la elevación de la proa, sino que también utiliza la misma perspectiva al dejarnos ver la cubierta.

En resumen, desde el punto de vista de la tecnología naval podemos concluir que la arboladura de un solo mástil, vela latina y calcés Tipo II sitúa a la embarcación n. ${ }^{\circ} 1$ de Laja Alta entre finales del s. XI y el XIV. El estudio de paralelos tipológicos del ámbito del Mediterráneo también apunta hacia una cronología acorde con lo anterior, siendo los más similares de comienzos del s. XIV y el xv. Por ello, proponemos para la nave n. ${ }^{\circ} 1$ de Laja Alta una horquilla entre los ss. XI-XIV.

\subsection{Barquiforme $n .^{\circ} 6$}

El motivo se encasilla en una zona fosilizada que aún no se ha desprendido del panel, hasta tal punto que esta condiciona parte de la morfología y tamaño de la nave (Fig. 11). Nos referimos con ello a la posición inusual del velamen, que se encuentra desplazado hacia lo que es la popa del barco, ajustándose a la máxima altura que permite la costra (Fig. 8). Como hemos indicado, existen pequeñas porciones de trazo de este velamen que sobrepasan la fractura (Fig. 6A), estas son un claro indicio que nos hace reflexionar sobre la datación prehistórica atribuida, mayoritariamente, hasta ahora. La perspectiva se asemeja a la embarcación n. ${ }^{\circ} 1$ en un intento de recrear el mismo efecto comentado.

Ediciones Universidad de Salamanca / 요
Carece de émbolo, aletas en popa y no se intuye calcés. Entre los elementos técnicos para su datación seleccionamos: la presencia de un solo mástil con vela latina y la morfología del casco. En referencia al velamen hemos determinado, al igual que el barco n. 1 de Laja Alta, que es de tipología latina en lugar de cuadrada. El criterio seguido para este pronunciamiento es la comparativa con los graffiti de época histórica. Las similitudes de la forma de representar el velamen en los barquiformes de Laja Alta con los múltiples paralelos medievales son muy elocuentes (Figs. 11A-B y 12A). La curvatura de popa, que se muestra más elevada que la proa, la comparten otros grafitos como los del Castillo de Santueri (Figs. 11C y 12c). Cabe indicar que cualquiera de las naves del Castillo de Santueri habría servido de modelo en la comparativa con las de Laja Alta. A su vez, este conjunto de grafitos tiene paralelos claros con las naves de la abadía de Montmajour en Arlés (Rigaud, 1996), donde encontramos barcos que se ajustan a las galeras propias de finales del s. XIII o principios del s. xIv. En cuanto a la perspectiva, el paralelo de la Fig. 11 в sugiere una coincidencia con la nave de Laja Alta. También es significativa la morfología almendrada de las palas en los remos para la que hemos hallado dos motivos gráficos afines $\mathrm{y}$ datados: una embarcación identificada por Barrera (2002) como 'cárabo', entre las que se conservan en la muralla del Albaicín entre los ss. XIV y XVI (Fig. 12B); y la galera в del Castillo de Santueri del s. XIII (Fig. 12C). En resumen, el único elemento tecnológico claro que podemos asumir es la vela latina, sumado a los paralelos iconográficos más afines que nos sitúan la nave entre los ss. XII-XVI.

\subsection{Barquiforme n. ${ }^{\circ} 5$}

La peculiaridad de esta nave reside en su popa, con unas líneas curvas y vistosas que la rematan (Fig. 13). Son ornamentaciones que, sin duda, se parecen en forma a las que lucen las naves clásicas griegas y romanas denominadas aplustres. Es posible identificarlas también en representaciones navales del periodo bizantino en Oriente y de la alta Edad 


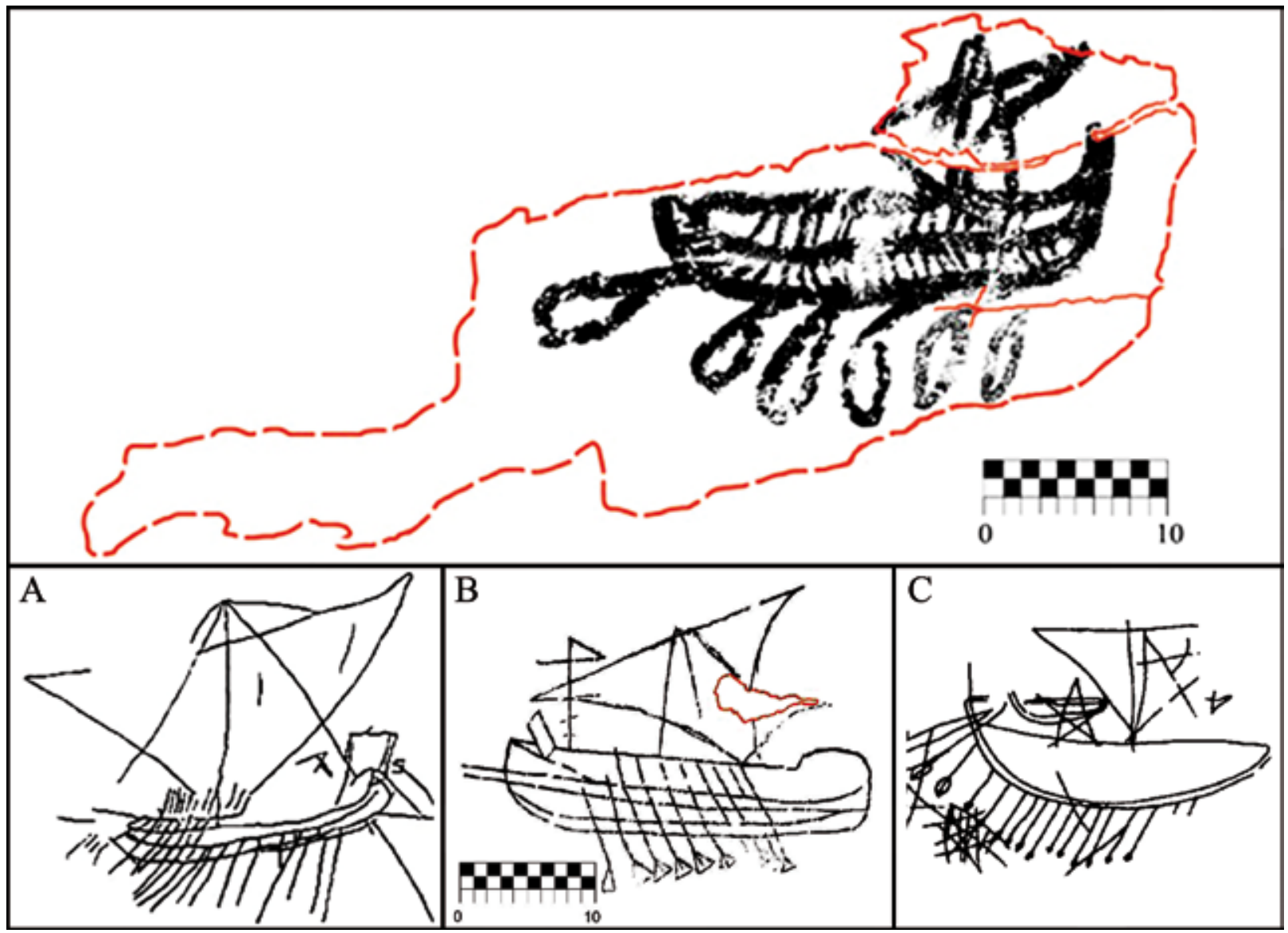

Fig. 11. Calco del barquiforme n. ${ }^{\circ} 6$ de Laja Alta y posibles paralelos: A) calco de grafito de una galera del castillo de Denia, Alicante, de los ss. XIV-XV (según Bazzana et al., 1984); B) calco de grafito de una galera del Castillo de Alcalá de Guadaira, Sevilla, del s. XVI (calco de elaboración propia a partir de la documentación de Cervera, 2008: 325); C) calco de grafito de una galera del Castillo de Santueri, s. XIII (segün González et al., 2000: 235).

Media en Occidente (Pryor y Jeffreys, 2006: 216). Este apéndice varía mucho en su diseño, se extiende desde el extremo de la popa elevándose hacia el interior de la embarcación sobre el timonel, en forma de abanico de diversas morfologías (Fig. 13c). El elemento acota una cronología con origen en el s. v a. C. Nuestra indagación se ha dirigido a conocer su continuidad y su final en las representaciones iconográficas. Los paralelos encontrados (Figs. 13Aв) nos muestran ornamentos similares. Pertenecen a miniaturas del manuscrito de Scilitza Matritensis -datado en el s. XII-, que contiene multitud de naves conocidas como dromones bizantinos, que podrían servir para establecer paralelos técnicos con las embarcaciones de Laja Alta. Estos dromones bizantinos son los antecedentes y el origen directo de las galeras occidentales. Por otra parte, encontramos otra similitud en el arrufo de proa del paralelo de la Fig. 13A, que presenta una elevación considerable y similar al barquiforme n. 5 de Laja Alta. Las miniaturas de barcos que hemos seleccionado como paralelos no portan velamen a diferencia del navío de Laja Alta, pero esta cuestión se relaciona con la abatibilidad del mástil en dromones o en galeras (Fig. 10c). Sobre los demás elementos técnicos de la nave n. ${ }^{\circ} 5$ de Laja Alta identificamos un calcés del Tipo II que, si bien no sigue la misma verticalidad del mástil, es posible que el límite de la fractura de la roca condicionara su posición dibujándose lateralmente. También determinamos que las velas son de 
Una nueva propuesta cronocultural

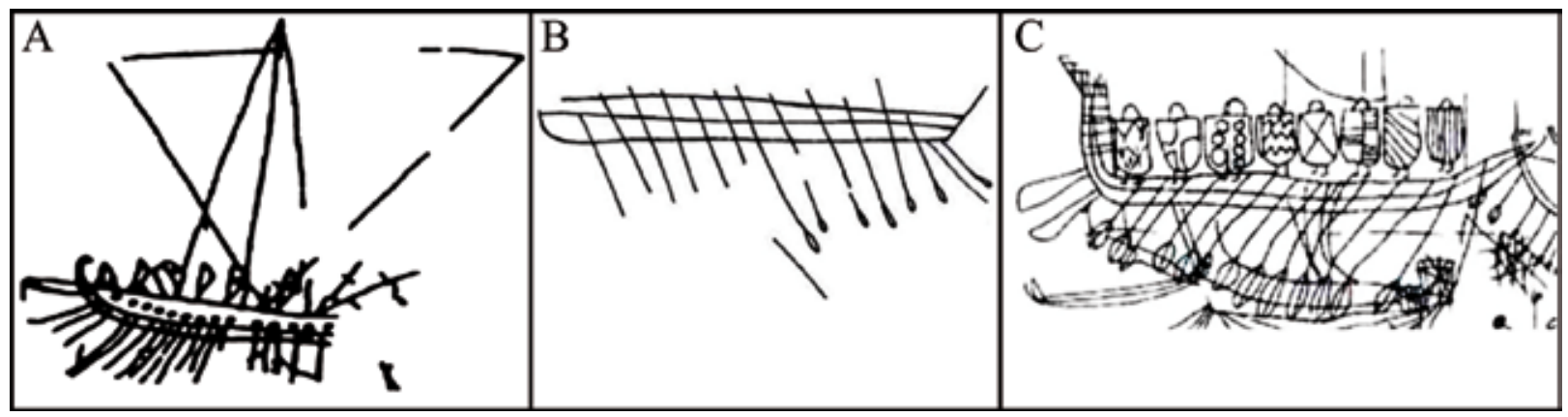

Fig. 12. Calcos de naves medievales con semejanzas a los de Laja Alta: A) calco de grafito de una galera del castillo de Denia, de los ss. XIV-XV (según Bazzana et al., 1984); B) calco de grafito de un cárabo de la muralla de Albaicín, Granada, de los ss. XIV-XV (según Barrera, 2002: 320); C) calco de grafito de una galera del castillo de Santueri, Mallorca, del s. XIII (según González et al., 2000: 234).

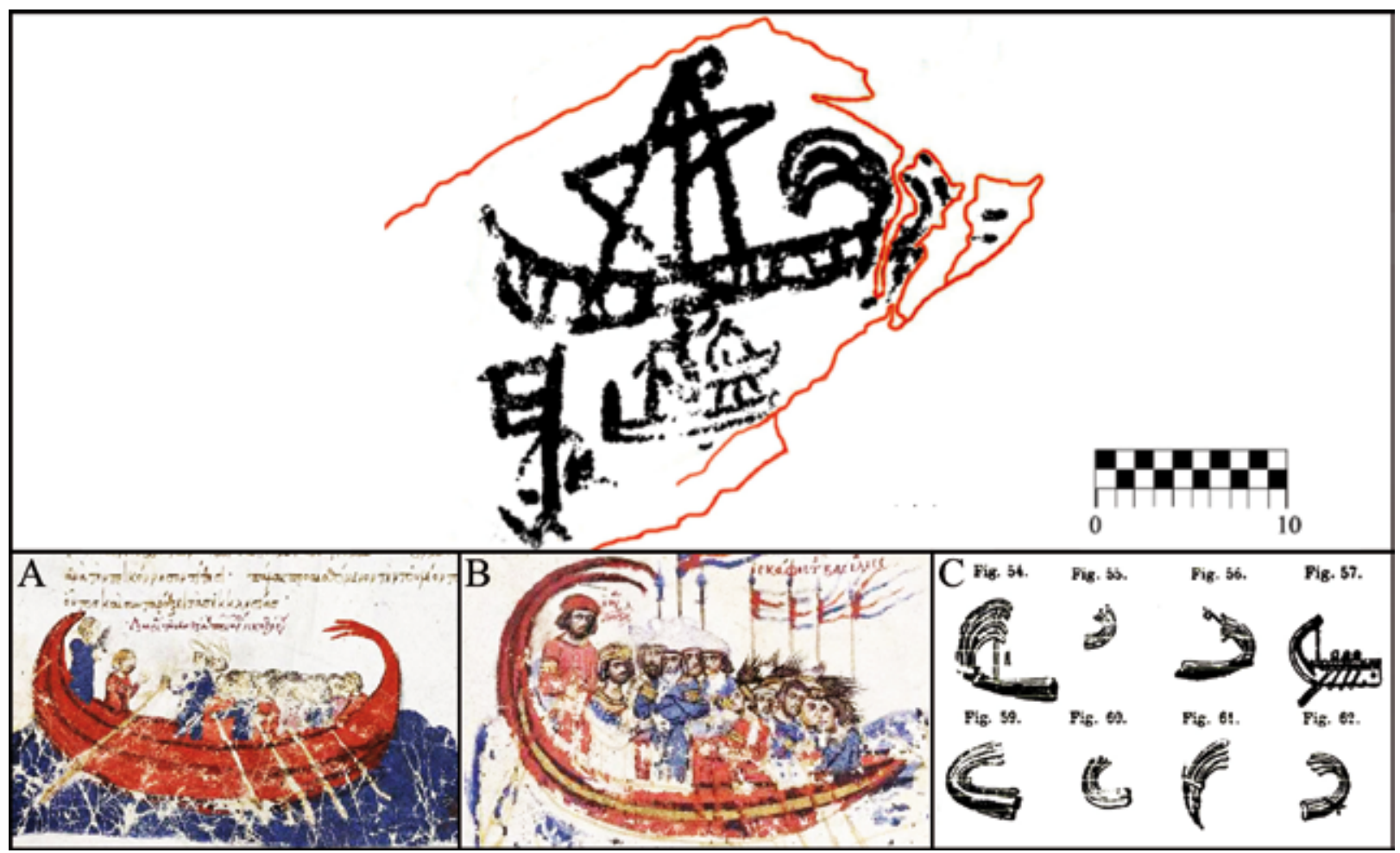

FIG. 13. Calco del barquiforme n. ${ }^{\circ} 5$ de Laja Alta y posibles paralelos: A-B) miniaturas de embarcaciones del s. XII (según Codex Graecus Matritensis Ioannis Skilitzes Ms VITR/26/2, f. 20r. yf. 41v., Biblioteca Nacional de España); c) morfología de los aplustres (Cartault, 1881).

tipología latina, con claros paralelos ya comentados en el barquiforme n. ${ }^{\circ} 6$ de Laja Alta. Este conjunto de características, donde incluimos un calcés tipo II, nos lleva a proponer unas fechas no anteriores al final del s. XI para esta embarcación. Existen otros motivos adyacentes a la embarcación en su parte inferior (Fig. 13). Son poco visibles, cuestión que ha repercutido en que estas figuras solo se vean reflejadas en tres de los cinco calcos publicados hasta ahora (Corzo y Giles, 1980; Morgado et al., 2018; 
Casado, 2019), pero también es observable en las imágenes con tratamiento digital de los trabajos de Martín Goërg y Martín Arrazola (2011 y 2012). Uno de estos motivos es clasificado como un pequeño barco (Corzo y Giles, 1980: 29), bote con vela (Martín Goërg et al., 2016) o barca (Morgado et al., 2018: 255). La actualización que hacemos de esta figura está en sintonía con las últimas publicaciones. En nuestra opinión su clasificación como barquiforme es coherente con lo representado, incluso parece observarse algún elemento náutico que no identificamos de forma clara, circunstancia que hace que no podamos ofrecer un análisis tecnológico de estos detalles con ciertas garantías. Un segundo motivo, a la izquierda del barco anterior y debajo de la proa del barquiforme n. ${ }^{\circ} 5$ de Laja Alta, nos recuerda una bandera con asta (Fig. 13). Es recurrente la presencia de estas banderas y banderines en los grafitis de motivos navales medievales; sin embargo, las valoraciones en trabajos de otros investigadores sobre esta figura van desde un ancla hasta alguna estructura portuaria, lo que nos muestra la dificultad en su identificación. En cualquier caso, no creemos que dicho motivo aporte datos significativos en nuestra propuesta de estudio del barquiforme n. ${ }^{o} 5$ de Laja Alta.

\subsection{Barquiforme n. ${ }^{\circ} 3$}

La nave se encuentra superpuesta a una mancha rojiza y a unos trazos del mismo color en popa (Fig. 14). Lo más relevante de este barco lo encontramos en la morfología de proa, su configuración se ha tomado como referencia para determinar su adscripción temporal y extrapolar esta datación al resto de los barquiformes: “... el triple espolón elevado se documenta en representaciones de época

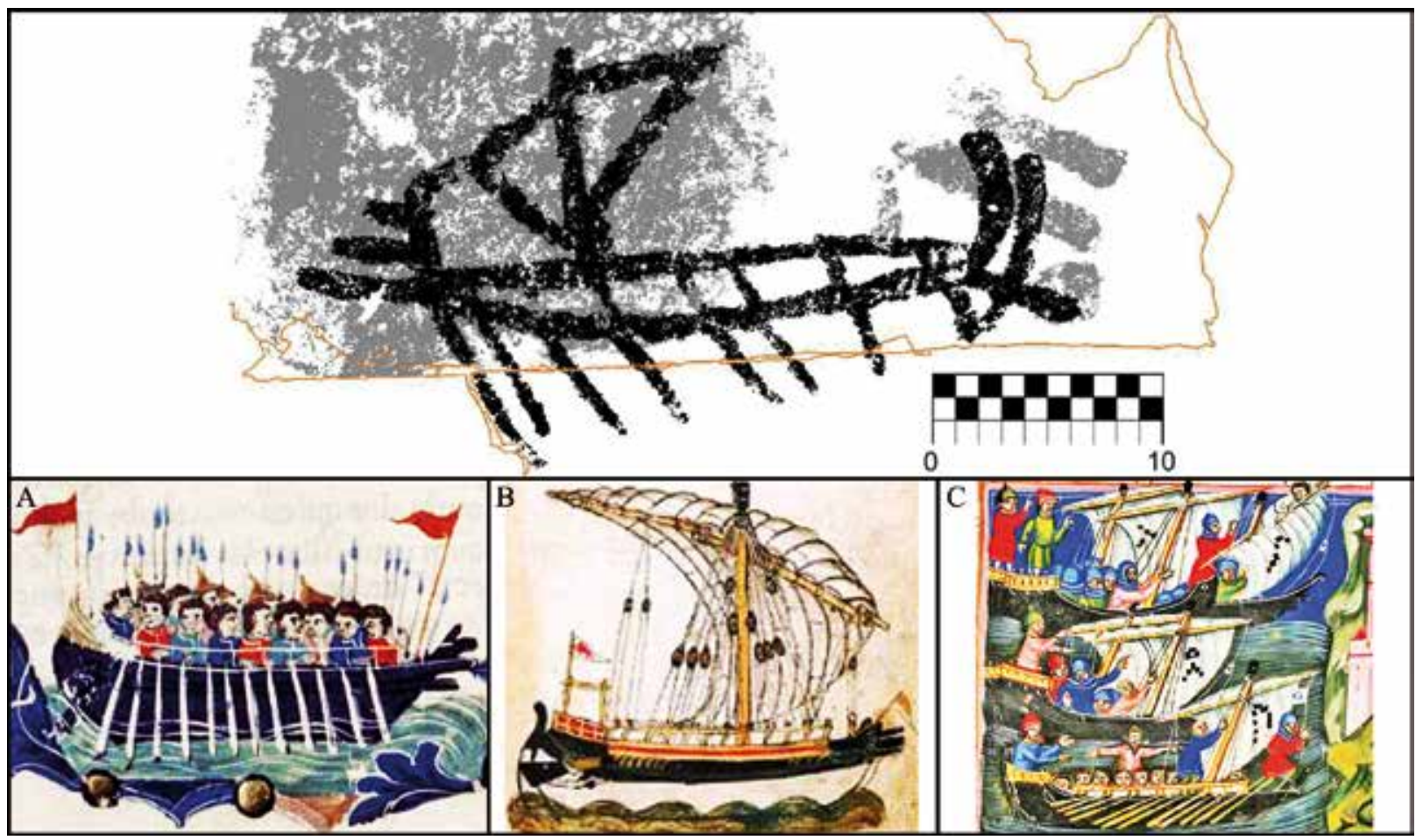

FIG. 14. Calco del barquiforme n. ${ }^{\circ} 3$ de Laja Alta y posibles paralelos: A) galera veneciana del s. XIV (según el Liber Secretorum Fidelium Crucis, Bodleian Library, Ms. Tanner 190, f. 20v.); B) galera veneciana del s. XV (segün Raixon dei Marineri, Biblioteca Nazionale Marciana, Ms.); c) galeras del s. XIV en manuscritos latinos de la Bodmeriana, Cologny-Genéve (segün http://www.e-codices.unifr.ch/en/cb/0078/38v/x-large; acceso 15/06/2019). 


\section{Una nueva propuesta cronocultural}

geométrica, pero nunca antes..." (Almagro, 1988: 390). En cambio, es un elemento que hemos podido rastrear en iconografía medieval (Fig. 14A-B y galera superior en C). Y también en estudios de tecnología naval medieval se afirma que "... saliendo de la roda de proa aparece un espolón formado por tres piezas paralelas en sentido horizontal, que dejan entre ellas un espacio para permitir la flexión del conjunto..."11. Este espolón va montado en embarcaciones clasificadas como galeras y fechadas entre el s. XIV y la primera mitad del s. xvi. En referencia a la popa, el último trazo oblicuo rompe la disposición paralela de los remos, además se solapa con las líneas curvas y equidistantes de esta zona. Podemos interpretarlo como un posible timón de espadilla. El timón de espadilla es uno de los elementos técnicos observable en embarcaciones de cualquier época, empieza a desaparecer con la aparición del timón de codaste -en el s. XIII-. Hay un periodo, entre los ss. XIII-XVII, en el que podemos encontrar embarcaciones en las que conviven los dos tipos de timones (Fig. 14B). Las líneas curvas y equidistantes que configuran la popa nos sugieren dos posibles lecturas. Por un lado, pueden tratarse de las aletas ya comentadas en el barquiforme n. ${ }^{\circ}$ 1. Por otra parte, puede ser que una de ellas, la más exterior, represente un timón de codaste. En ambos casos tiene sus paralelos claros en iconografía medieval, sirvan de ejemplo los paralelos в у c de la Fig. 14 para el timón de codaste y los paralelos в y C de la Fig. 10 para las aletas. Respecto a la vela, entendemos que es difícil determinar si esta figura de cuadrilátero irregular puede clasificarse de tipo latino, pero tampoco es la forma habitual de dibujar la vela cuadra. Lamentablemente no se observan aparejos y cabos para poder inclinarnos por alguna de las opciones. La nave de Laja Alta se dibuja con propulsión mixta compatible con cualquier galera medieval o de otra época. En conclusión, la combinación sobre la concordancia iconográfica de los apéndices triples del émbolo, sumada a la datación de este elemento tecnológico náutico, nos sitúa la embarcación n. ${ }^{\circ} 3$ entre los ss. XIV y XV.

11 Fondevila, op. cit. n. 7, p. 133.

\subsection{Barquiforme.$^{\circ} 2$}

Situado encima de la misma mancha de pigmento rojizo, resulta muy difícil encontrar un paralelo claro para este barquiforme por su grado de esquematismo (Fig. 15). No hemos encontrado nada parecido en tiempos prehistóricos, y la nave más similar en tiempos anteriores a la Edad Media pudiera ser la localizada en Ostia Antica (Fig. 15c). La representación de los cabos de este barco, distribuidos a lo largo de la borda, es semejante a la de la embarcación n. ${ }^{\circ} 2$ de Laja Alta; no obstante, difiere en la configuración del casco. Nos parecen más adecuados los paralelos IA y IIA (Fig. 15), grabados en la cara interior y exterior de un sarcófago de piedra atribuido al s. XII (Coppola y Marín, 1990: 106). Las semejanzas gráficas con estas dos últimas naves las basamos en la forma de representar los aparejos y el casco, con el mismo grado de simplicidad. Otro posible paralelo, en cuanto a la forma de dibujar el aparejo latino, lo encontramos en el barco pintado de uno de los ábsides del monasterio de Santa María de Poblet en Conca de Barberá, Tarragona (Fig. 15B). Los cabos nos muestran una distribución similar, pero incluye la entena trazada en sentido transversal al mástil, del que carece la nave de Laja Alta. Esta cuestión nos sugiere que la configuración de líneas observables en el barquiforme n. 2 es compatible con el velamen de tipología latina. Otro detalle de la embarcación n.o 2 es un gran aro en la parte superior del mástil, susceptible de ser identificado como un calcés de Tipo II o como una cofa. Si es un calcés tendríamos una datación clara para este elemento tecnológico. En cambio, si es una cofa, su datación es muy extensa y puede ir acompañada de cualquier tipología de velamen. Pero la representación de la vela cuadra en la iconografía se aleja mucho de lo que observamos en el barquiforme n. ${ }^{\circ} 2$ de Laja Alta. Caben más interpretaciones sobre algunas líneas que parecen configurar una proa oval en la nave n. ${ }^{\circ} 2$ de Laja Alta, a partir de la cual se podría admitir que representa una vela latina empopada. Esta lectura se hace por la comparativa con la galera incisa hallada

Zephyrus, LXXXVIII, julio-diciembre 2021, 209-234 


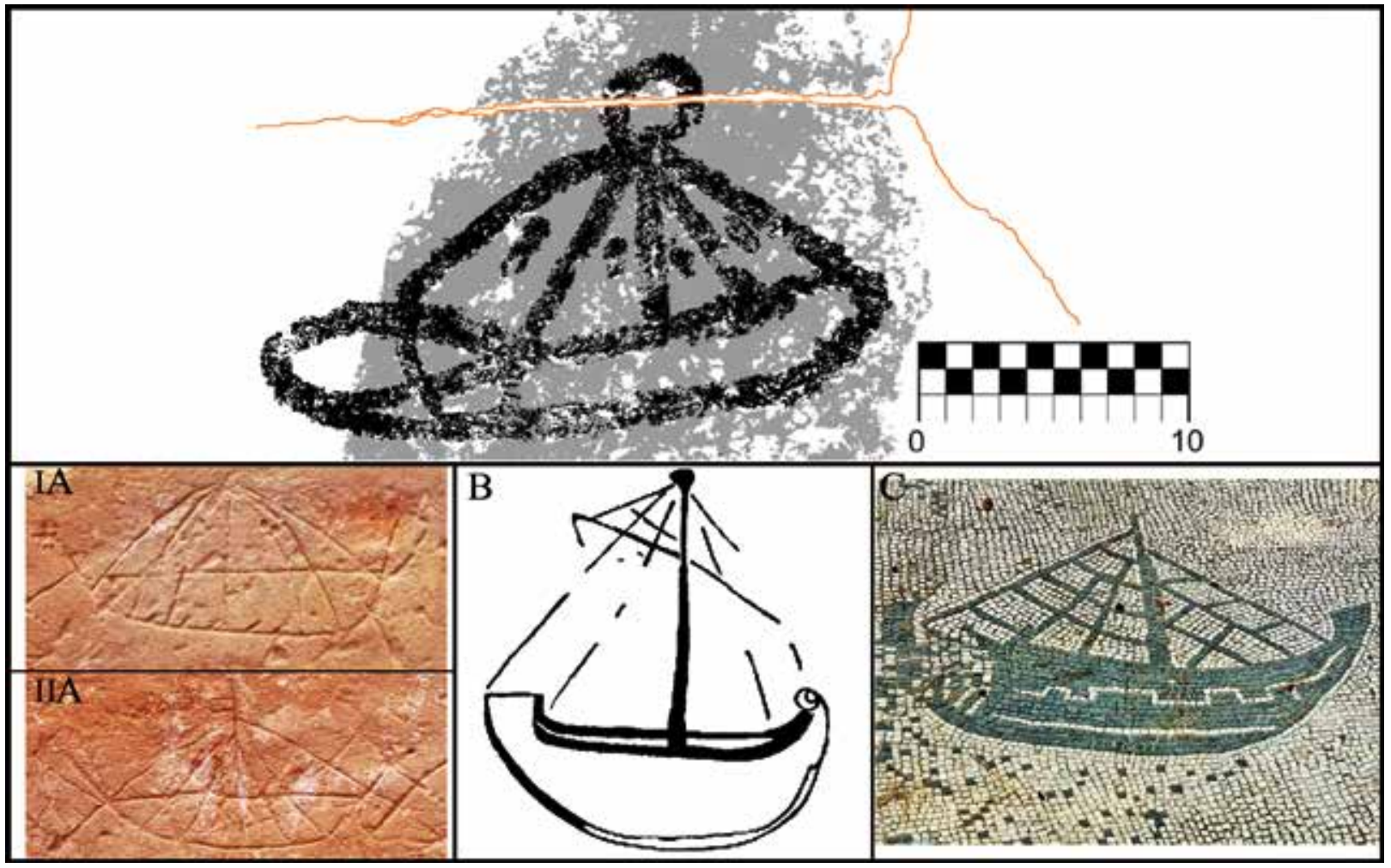

FIG. 15. Calco del barquiforme n. ${ }^{\circ} 2$ de Laja Alta y posibles paralelos: IA y IIA) naves incisas en un sarcófago del s. XII de la iglesia de Saint-Pierre d'Hérouville Saint-Clair (según http://www.unicaen.fr/recherchelmrsh/forge/1254; acceso 1/05/2018); B) barco pintado en el ábside del monasterio de Santa Maria del Poblet, del s. XV (según Casanova y Rovira, 1999: 29); C) nave en mosaico romano del Foro delle Corporazioni de Ostia, Roma (según https:/lfr.wikipedia.org/wiki/Navigation_ dans_l\%27Antiquit\%C3\%A9; acceso 1/05/2018).

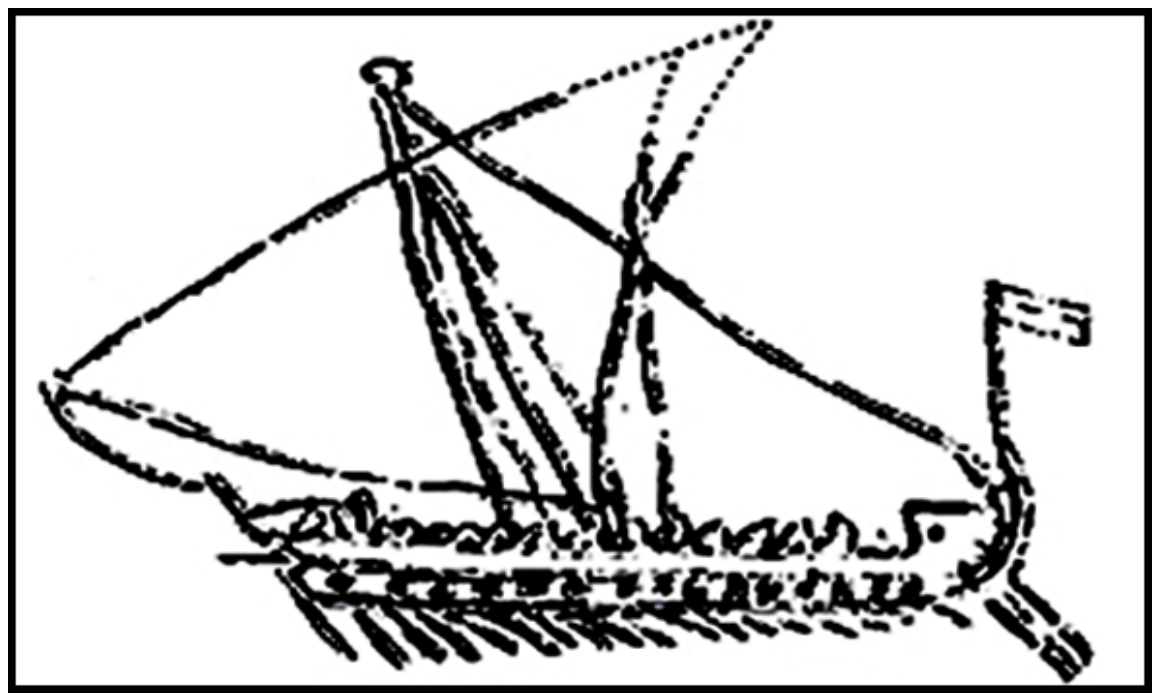

Fig. 16. Calco de una galera incisa en la alcazaba de Málaga datado por Fondevila (2018: 114) en el s. XIII (según Konstam, 2015: 35). 
Una nueva propuesta cronocultural

en la Alcazaba de Málaga (Fig. 16). En el grafito observamos cómo se traza una figura ovalada que recrea el efecto que produce el viento al empopar una vela de tipología latina. Además, la distribución de cabos de esta nave es compatible con lo representado en el barquiforme n. ${ }^{\circ}$, y estos van a converger claramente al calcés. Por último, para los trazos, alguno en forma de digitación, que se observan entre las líneas que configuran el velamen, visibles solo tras tratamiento digital, no tenemos interpretación como elemento náutico. Atribuir una cronología precisa para esta embarcación por los elementos de tecnología naval es difícil, pues no se refleja ningún elemento tecnológico claro. Establecemos una horquilla temporal entre los ss. XI-XIV si aceptáramos la identificación del calcés de Tipo II, por los paralelos iconográficos más afines se puede datar entre los ss. XII y XIII.

\subsection{Barquiforme.$^{\circ} 7$}

Es el último por su posición en el panel y se sitúa en el extremo derecho de la escena naval (Fig. 7). Es una nave que vuelve a adaptarse a la costra fosilizada, hasta el punto de que encontramos trazos fuera de este panel fósil (Fig. 6в). Navega hacia la izquierda, como todos los demás barcos de la escena, son los detalles del émbolo en la proa y la morfología de la popa curvada, con dos aletas, lo que determina esta suposición (Fig. 17). Identificamos un mástil, los cabos de sujeción anclados a los laterales, émbolo de proa, remos, un banderín en popa y un posible timón de espadilla. Para nuestro análisis tecnológico, una evidencia importante es el trazo en la proa que sobresale longitudinalmente de la línea que dibuja la borda, prolongándose a modo de apéndice. Lo interpretamos como la representación de un émbolo o espolón, que queda

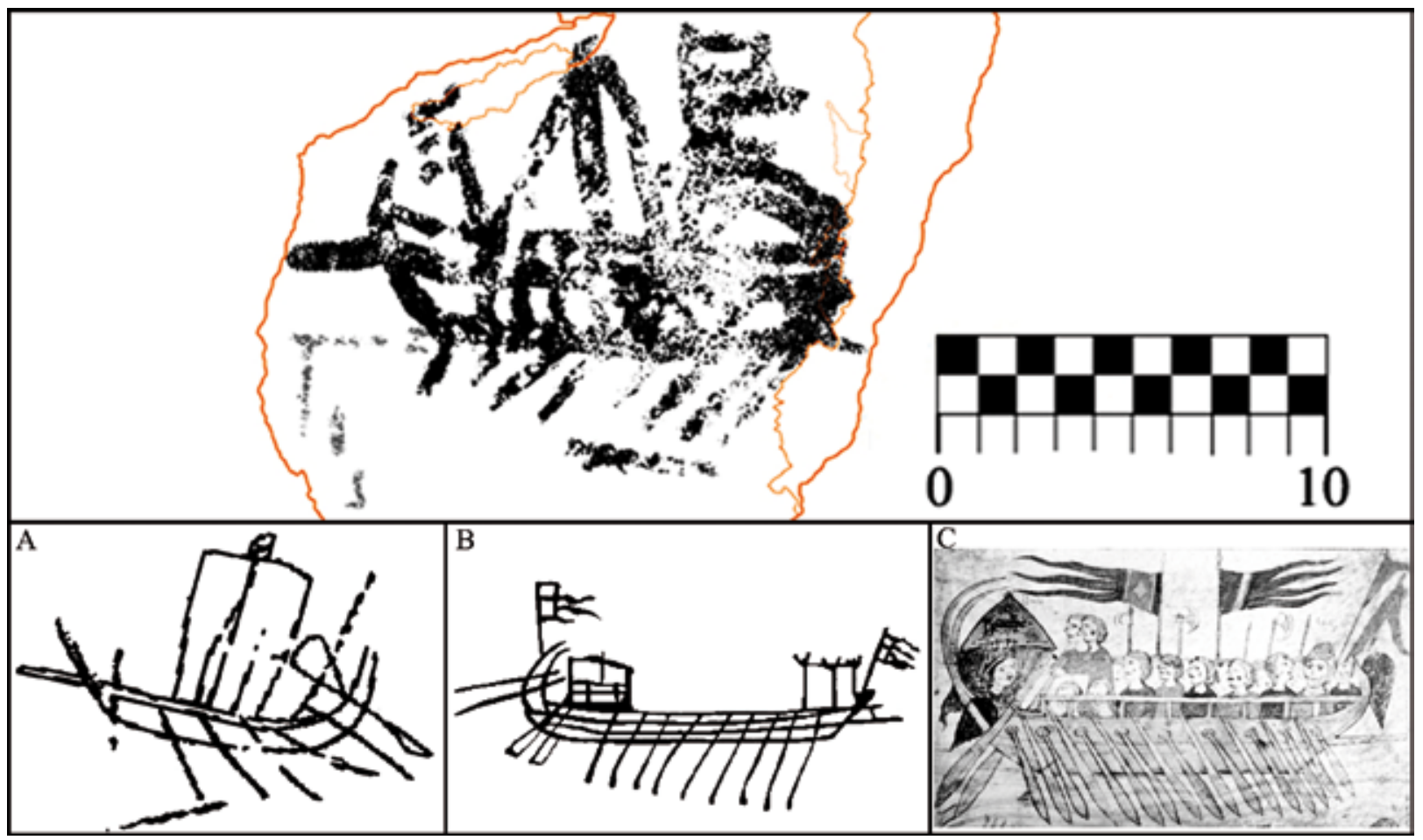

FIG. 17. Calco del barquiforme n. ${ }^{\circ} 7$ de Laja Alta y posibles paralelos: A) calco de una fusta grabada en el s. XIV sobre el enlucido de la muralla del Albaicin, Granada (según Casado, 2003: 539); B) galera veneciana del s. XIII en manuscrito de State Archive Santo Stefano, Venezia (según Nakas, 2013: 191); C) galera siciliana del manuscrito del s. XIII Liber ad honorem Augusti sive de rebus Siculis (según Fondevila, 2018: 104). 
claramente por encima de la línea de flotación del barco. Es una pieza que surge en los primeros dromones bizantinos y se adopta en las galeras medievales. Este elemento técnico está bien acotado en el tiempo, las galeras mantienen el émbolo hasta el $s$. XIII como muestra la iconografía (Fig. 17 B-C), hasta que hace su aparición el espolón del s. XIV ${ }^{12}$ (Fig. 17A). En la popa del barco de Laja Alta observamos peculiaridades recurrentes de las galeras de cronología medieval. La doble línea curvada -aletas- hacia el interior son formas estandarizadas que sobreviven, según las fuentes iconográficas, hasta inicios del s. XIV. Respecto a la arboladura no se aprecian velas ni calcés, solo el mencionado mástil y obenques, lo que no nos aporta información relevante. Tampoco podemos aventurar una interpretación fiable del trazo inclinado en proa y rematado con tres líneas paralelas. No obstante, encontramos algo parecido en el paralelo de la Fig. 17в, identificado como un gallardete con flecos. En la parte trasera sí aparece un signo que podría corresponderse con un banderín de popa. De ser así, tal motivo no suele representarse en el paradigma tipológico de la iconografía prehistórica, pero su presencia es muy frecuente en naves de cronología histórica, especialmente medievales (Figs. 14 A-B, 16 y 17B-C). Otro elemento que sugiere la necesidad de una relectura es el último trazo en popa que rompe la disposición de los remos. Pensamos que podría tratarse de un timón de espadilla o de un émbolo de popa. En cualquier caso, son componentes que comparten las galeras medievales. Por último, en la proa de la embarcación n. 7 de Laja Alta distinguimos una roda sobreelevada, elemento que está presente en algunas galeras medievales y es recurrente en su representación (Fig. 17 A-C).

En conclusión, creemos que el barquiforme n. ${ }^{\circ}$ 7 es una galera con presencia de un único mástil y aletas, elementos propios de los ss. XII-XIV, una cronología compatible con las fechas del espolón y demás elementos identificables. Los paralelos propuestos coinciden con estas fechas y esta es la horquilla temporal que proponemos.

12 Fondevila, op. cit. n. 7, p. 325.

\subsection{Barquiforme n. ${ }^{\circ} 4$}

Es la nave construida con menor detalle: casco, proa con roda alzada, popa con morfología curvada y una línea de remos (Fig. 18). No podemos precisar si ha perdido algún rasgo morfológico a causa del desprendimiento de panel en la proa. A pesar de esta simplicidad, es el barquiforme al que encontramos más paralelos y los localizamos en cualquier tipo de soporte y técnica. Su tamaño ha influido en otros autores para otorgarle la característica de nave auxiliar, sin embargo, las semejanzas con las imágenes mostradas (Fig. 18A-C) nos aseveran que su forma es compatible con la de una galera. La ausencia de mástil está presente en la iconografía, hay que recordar que este es abatible ya que son naves de propulsión mixta. En la popa del navío n. ${ }^{\circ} 4$ se advierte una doble línea curvada equidistante y revirada hacia el interior que nos recuerda a las aletas, atributo común de las galeras mediterráneas hasta el s. XIv. Las imágenes seleccionadas como paralelos cumplen con la sencillez en su morfología gráfica, similar a la embarcación n. 4 de Laja Alta. En la proa, algunos de los paralelos propuestos poseen émbolo, pero es posible encontrar proas alzadas sin émbolo (Fig. 18A), o pudiera darse el caso de que la nave de Laja Alta lo hubiera perdido por descamación de soporte. En conclusión, a pesar de la sencillez representativa del barco n. ${ }^{\circ} 4$ de Laja Alta, este tiene claros paralelos en la representación de galeras de los ss. XII y XIII. El atributo técnico de las aletas curvadas nos marca un máximo horizonte del s. XIV. La cronología propuesta para esta nave se sitúa entre los ss. XII-XIV.

\section{Síntesis y conclusiones}

El abrigo de Laja Alta es un referente a nivel nacional e internacional en los estudios de la navegación prehistórica. Las incógnitas sobre la motivación de su creación, sumadas a su señalada excepcionalidad tipológica en el ARE, tanto de los barcos como de su gestación en escena naval, son el incentivo para que especialistas en navegación prehistórica

Zephyrus, LXXXVIII, julio-diciembre 2021, 209-234 


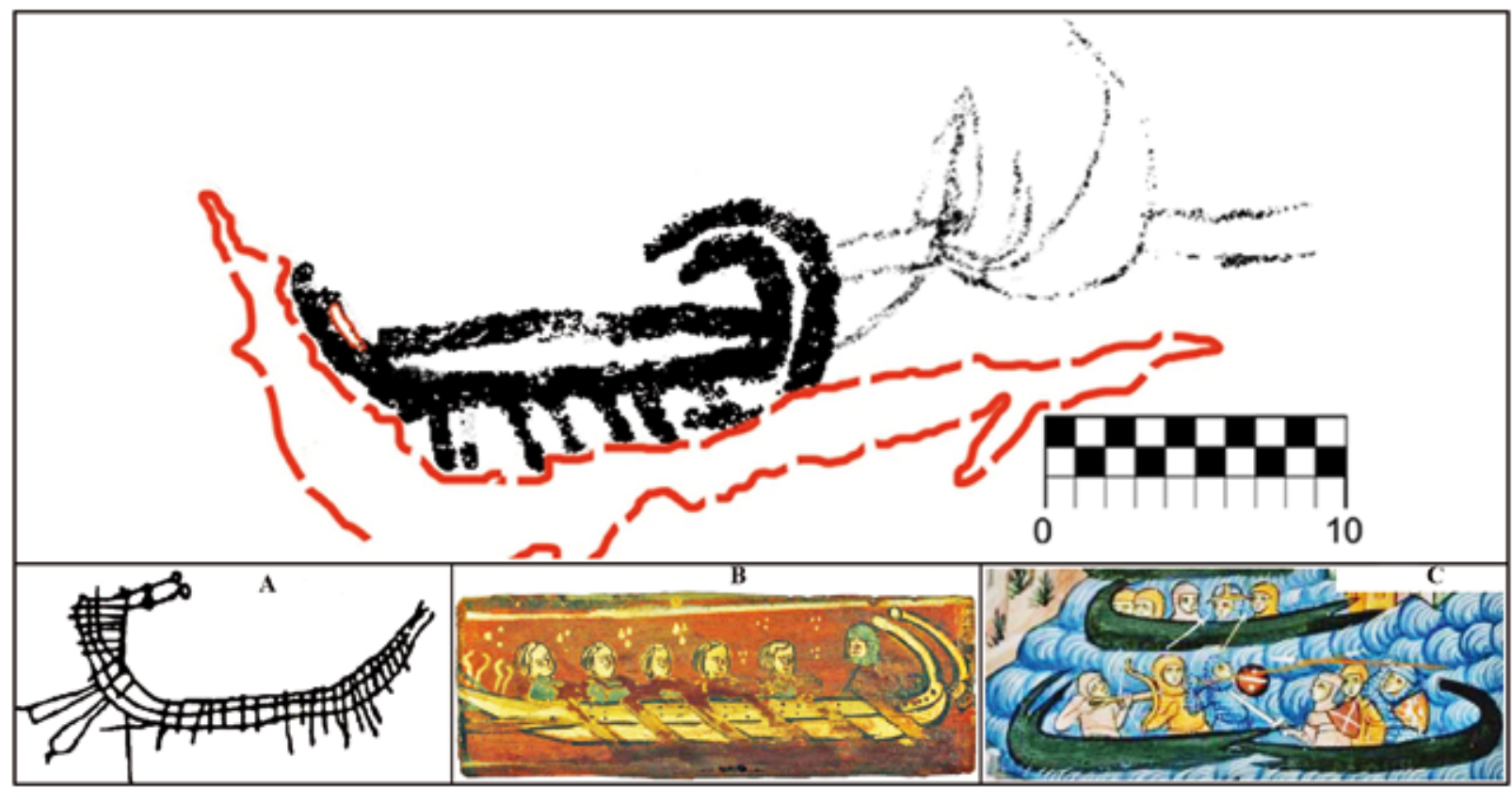

Fig. 18. Calco del barquiforme n. ${ }^{\circ} 4$ de Laja Alta y posibles paralelos: A) calco del grafito de una galera del castillo de Santueri, Mallorca, del s. XIII (según González Gonzalo et al., 2000: 233); B) galera sobre tablilla del s. XIII (Museo Nacional d'Art de Catalunya, n. ${ }^{\circ}$ catálogo: 107881, Barcelona); c) galeras en miniatura del s. XIII (según Livre des Ansienes Estoires, British Library, BL Additional 15268, f. 136v.).

hayan construido diferentes teorías sobre su existencia. La rotundidad del contexto hizo que, desde un principio, quedase marcado conceptualmente como yacimiento prehistórico, dificultando cualquier valoración de especialistas fuera de este ámbito. Las teorías han ido cayendo en cascada a partir de estos primeros diagnósticos, sin tener en cuenta las múltiples contradicciones internas en su ejecución y tipología. Consideramos que las connotaciones del término 'arte rupestre' han limitado no solo el estudio de algunas manifestaciones gráficas históricas, sino su adscripción exclusiva al paradigma del arte prehistórico forzando, en ocasiones, una interpretación adecuada a tal cronología. En este trabajo hemos intentado superar este 'determinismo del soporte’ (Martínez García, 2003: 77), abordando el estudio de las embarcaciones como objetos gráficos. Esto nos ha llevado a demostrar que todos aquellos elementos técnicos que han servido para adjudicar una cronología prehistórica de las naves pueden justificarse y encajar con los conocimientos que

Ediciones Universidad de Salamanca / 용 tenemos de la tecnología naval medieval. Por otra parte, los paralelos iconográficos más afines encontrados en distintas fuentes y soportes se encuentran bien delimitados en la Baja Edad Media. Todo esto nos lleva a poder afirmar que las naves se enmarcan en una horquilla cronológica entre los ss. XII al XIV, pudiendo corresponderse con embarcaciones de la familia tipológica de las galeras (Fig. 19). Esta interpretación que proponemos vuelve a plantear un debate que se amplía con los estudios que puedan realizar especialistas de época histórica. Las imágenes que nos muestran trazos con continuidad fuera de costras fosilizadas, sobre roturas de panel y que hasta ahora habían pasado desapercibidas no son solo una evidencia que nos tendría que hacer reflexionar sobre la antigüedad de estas naves, sino que nos advierte de procurar unas reproducciones digitales lo más minuciosas y fidedignas posibles, donde debe incluirse una mínima representación de la tafononía de la pared rocosa en los calcos. Gracias a ello, se han obtenido datos relevantes 


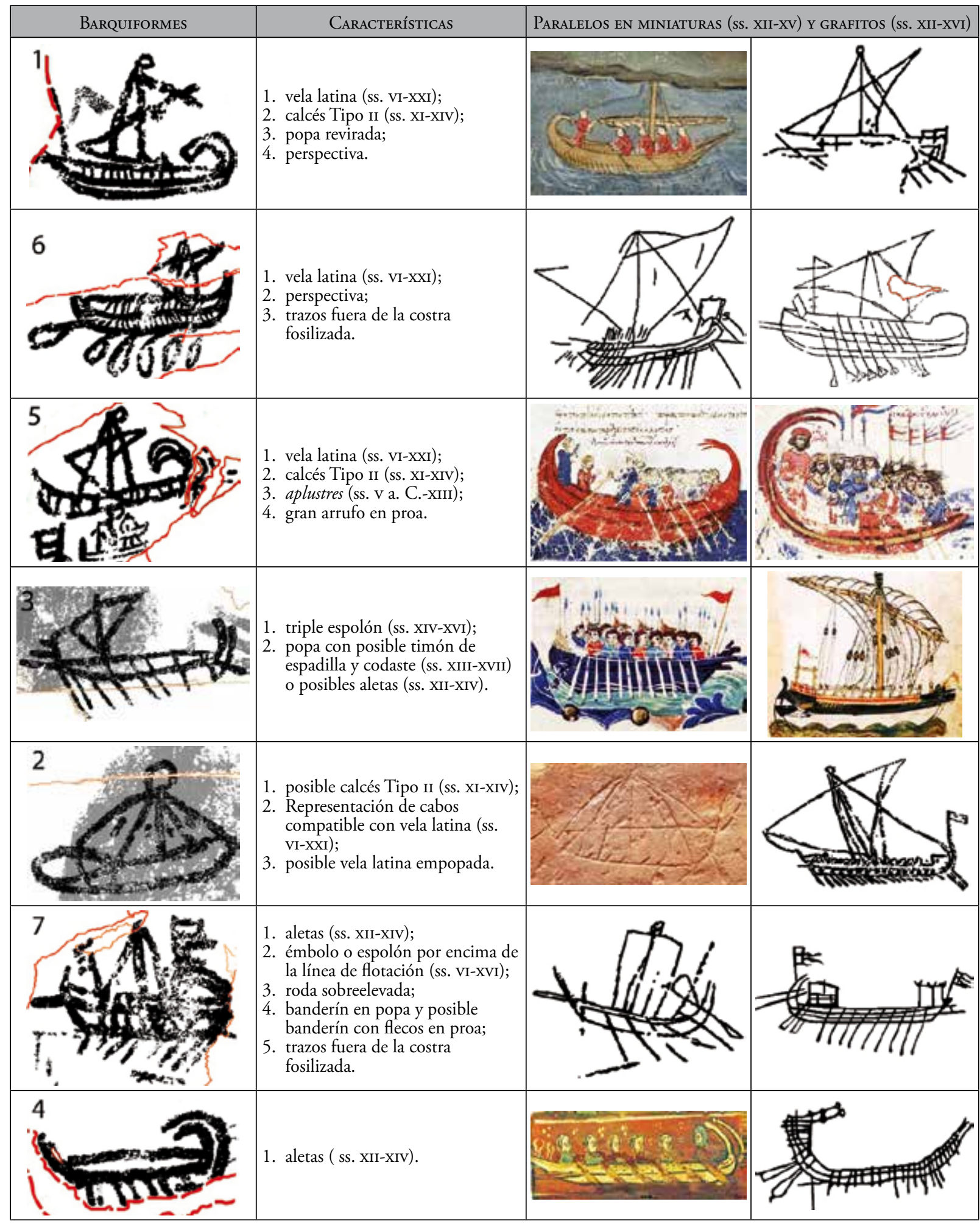

Fig. 19. Resumen de paralelos y conclusiones. 
sobre algunos motivos del abrigo de Laja Alta que nos sugieren un carácter de imitaciones (Fig. 2A) y de manifestaciones de cronología histórica (Fig. 2в). Estas no son figuras descontextualizadas, pues, además de la existencia de múltiples cuevas con falsificaciones de arte rupestre prehistórico, hemos encontrado ejemplos de motivos históricos en las sierras de Cádiz, que atestiguan el uso de los abrigos como soporte de manifestaciones gráficas y epigráficas ejecutadas en las técnicas de grabado y pintura hasta tiempos contemporáneos. Nuestra labor de campo en este ámbito geográfico nos lleva al firme convencimiento de la existencia de motivos en pigmento rojo que están engrosando este corpus del ARE sin ser prehistóricos, y los barcos de Laja Alta no serían una excepción. Conocer las representaciones gráficas prehistóricas de la zona gaditana y sus singularidades con superficialidad solo ha creado más incertidumbre al conocimiento del abrigo de Laja Alta. Hecho que se demuestra con la tesis aceptada de la existencia de una concentración única de grafías navales en Cádiz. Nos referimos a la existencia de seis enclaves con barcos en pigmento rojo que crean un microcontexto de iconografía naval en el Campo de Gibraltar, el cual ha servido como pretexto para acomodar los naviformes de Laja Alta en tiempos prehistóricos. En este trabajo queremos dejar constancia de lo desarcertado de este planteamiento, que tiene su origen en unos calcos e interpretaciones erróneos (Fig. 5). Sobre el estudio de los grafitos, entendemos que son un acto de expresión espontánea en unas circunstancias concretas de uso de los espacios, en las que la forma de representar los objetos es, principalmente, el esquematismo y que, en el caso de los grafitos pintados, predomina el monocromatismo. El carácter de espontaneidad e improvisación de esta manifestación cultural no limita la elección del soporte, antes bien, lo amplía y no parece haber una relación entre ubicación, soporte y técnica. Creemos que en el abrigo de Laja Alta la disponibilidad de pigmentos in situ -fragmentos rojizos de arenisca ferruginosa- determinó la selección técnica y posiblemente el autor o autores se vieran animados por la presencia de otras figuras anteriores. Como resultado observamos unas

Ediciones Universidad de Salamanca / 요 representaciones en las que la pericia gráfica, entendida como expresión figurativa, no es relevante. Estas particularidades le confieren al grafito histórico unas características que, a pesar de estar alejados del código cultural oficial de la época en que estén contextualizados, siguen un sistema de representación, entendiendo este concepto como un conjunto de normas, quizá más psicológicas que culturales, y que pueden involucrar, entre otros aspectos, perspectiva, horizontalidad en la presentación de escenas o selección temático-tipológica. Estas premisas nos llevan a poder decir que los motivos navales y la escena que componen en la Laja Alta siguen los patrones de una acción gráfica determinada en un periodo y se ajustan a los modos de representación del fenómeno en el que se enmarcan. Hay que señalar que, dentro del paradigma tipológico del grafito, las embarcaciones son uno de los motivos más representados en época histórica (García Serrano, 2012: 41) y, en concreto, disfrutan de una mayor presencia en las épocas medieval y moderna, tanto en España (Royo y Gómez, 2002: 64; Ozcáriz, 2008: 293) como en el ámbito geográfico europeo (Gerrard, 2006: 339). Si bien los barcos dominan en aquellas localizaciones geográficas con acceso directo al mar (Barrera, 2011: 30), no es extraño encontrar motivos tierra adentro, siendo uno de los ejemplos más evidentes la nao realizada en pigmento ocre de la cueva del Esquilo en Moratalla (Eiroa, 1991-1992; Mateo, 1993). Concluimos que los barcos de Laja Alta no deben ser adscritos al arte esquemático como concepto crono-cultural. Efectivamente, han sido ejecutados con el sistema de representación gráfica del esquematismo, que debe ser entendido como un procedimiento universal y atemporal. Este recurso, alejado de toda adscripción cronológica y ajeno a concepciones culturales, se observa no solo en la Historia del Arte, sino en cualquier campo en el que la comunicación humana se involucre. En definitiva, este trabajo muestra las primeras evidencias de graffiti rupestres en la provincia de Cádiz. Con los ejemplos mostrados, advertimos de la presencia de grafías medievales, en este ámbito geográfico, que tradicionalmente han engrosado el corpus de manifestaciones rupestres

Zephyrus, LXXXVIII, julio-diciembre 2021, 209-234 
prehistóricas y, por tanto, se impone la necesidad de tener en consideración esta variable por parte de los investigadores de arte rupestre prehistórico. Bajo estos principios, los paneles de Laja Alta se convierten en un excepcional modelo que nos puede reportar una mejor perspectiva para acrecentar nuestra comprensión de un mundo tan complejo, debido a su universalidad y diacronía, como son las manifestaciones gráficas en contexto rupestre de carácter esquemático prehistóricas e históricas.

\section{Fuentes medievales}

Alfonso X: Cantigas de Santa María. Ms. B.R. 20. Biblioteca Nazionale Centrale de Florencia (https:// datos.bne.es/edicion/bimo0000176701.html; acceso 11/06/2018).

Alfonso X: Cantigas de Santa María Códice Rico. Ms. T-I-. Real Biblioteca del Monasterio de San Lorenzo de El Escorial (https://rbdigital.realbiblioteca.es/s/ rbme/item/11337; acceso 13/06/2018).

Anónimo: Li Livre des Ansienes Estoires. BL Additional, 15268. British Library. London (http://www.bl.uk/ manuscripts/FullDisplay.aspx?ref=Add_MS_15268; acceso 14/06/2018).

DA EвоLI, P.: Liber ad honorem Augusti sive de rebus Siculis. ввв Cod. 120.II (https://manuscriptminiatures. com/3966/11591; acceso 18/06/2018).

De Rodas, M.: Raxion de Marineri. Ms. Ital., cl. IV, cod. 170. Biblioteca Nazionale Marciana. Venezia (https://bibliotecanazionalemarciana.cultura.gov.it/ la-biblioteca/biblioteca-digitale; acceso 11/06/2018).

Sanuto, M.: Liber Secretorum Fidelium Crucis. Ms. Tanner 190. Bodleian Library. Oxford (https://digital. bodleian.ox.ac.uk/objects/43fcfa94-aee7-4ec6-9330b2729225905c/surfaces/6d9f788f-9060-4e9b-ad78a3e97a90968e/; acceso 10/06/2018).

Skillitzes, I.: Codex Graecus Matritensis Ioannis Skillitzes. Ms. VITR/26/2. Biblioteca Nacional de España. Madrid (https://manuscriptminiatures. com/4203/13408; acceso 11/06/2018).

\section{Bibliografía}

Acosta, P. (1984): "El arte rupestre esquemático ibérico: problemas de cronología preliminares". En ForTEA,
J. (coord.): Scripta Praehistorica Fco. Jordá Oblata. Salamanca: EUSAL, pp. 31-62.

Almagro Gorbea, M. (1988): "Representaciones de barcos en el arte rupestre de la Península Ibérica. Aportación a la navegación precolonial desde el Mediterráneo Oriental”. En Ripoll, E. (ed.): Actas Congreso Internacional del Estrecho de Gibraltar (Ceuta, 1987). Vol. I. Prehistoria e Historia de la Antigüedad. Madrid: UNED, pp. 389-398.

Almagro Gorbea, M. (1995): "La navegación prehistórica y el mundo Atlántico". En Guerra, exploraciones y navegación: del mundo antiguo a la edad moderna. Ferrol: Univ. da Coruña, pp. 13-36.

Alonso, F. (2011): "Embarcaciones prerromanas del área Atlántica Europea”, Anuario Brigantino, 34, pp. 93-158.

Aubert, C. (1999): "Les représentations navales de Laja Alta en Andalousie", Tropis, v, pp. 31-41.

Barrera, J. I. (2002): "Graffiti en la muralla del Albayzín”, Arqueología y Territorio Medieval, 9, pp. 289-328.

BArrera, J. I. (2011): "Barcos, peces, estrellas y otros motivos en los muros del castillo de Almuñécar (Granada)". En Actes XVII Colloque International de Glyptographie (Cracovie, 2010). Braine-le-Château: Éd. de la Taille d'Aulme, pp. 27-46.

Barroso, C. (1978): "Nuevas pinturas del abrigo de Laja Alta", Jábega, 24, pp. 3-8.

Barroso, C. (1980): "Nuevas pinturas rupestres en Jimena de la Frontera: Abrigo de Laja Alta", Zephyrus, XXX-XXXI, pp. 23-42.

Bazzana, A.; Lamblin, M. P. y Montmessin, Y. (1984): Los grafitis medievales del Castell de Dénia. Catálogo. Dénia: Ayto. de Dénia.

Bergmann, L. (1995): "Nuevas cuevas con pintura rupestre en el término municipal de Tarifa", Almoraima, 13, pp. 51-64.

Broodbank, C. (2013): The Making of the Middle Sea, A History of the Mediterranean from the Beginning to the Emergence of the Classical World. London: Thames and Hudson.

Carsson, L. (1971): “The origin of the lateen”, American Neptune, 31, pp. 30-60.

Cartault, A. (1881): La trière athénienne, étude dàrchéologie navale. Paris: E. Thorin.

Casado, A. (2019): "La Laja Alta: revisión y propuesta de protección”, Almoraima, 51, pp. 115-129.

Casado, J. L. (2003): "El Cantábrico y las galeras hispanas de la Edad Media a la Moderna”, Revista de Estudios Maritimos del País Vasco, 2, pp. 537-552. 
Casado, J. L. (2012): "Panorama tipológico de los barcos ibéricos en la época de las Cantigas de Santa María", Alcanate: Revista de Estudios Alfonsies, 8, pp. 191-219.

Casanovas, A. y Rovira, J. (1999): Grafits, 6000 anys de llenguatge marginal. Barcelona: Fund. Caixa-Sabadell.

Cervera, L. (2008): "Graffiti de tema marítimo en el Castillo de Alcalá de Guadaira (Sevilla)". En Congreso Internacional sobre fortificaciones (4, 2007): Las fortifcaciones y el mar. Alcalá de Guadaira: Ayto. Alcalá de Guadaira, pp. 321-328.

Coppola, G. y Marin, J. Y. (1990): "Les signes lapidaires sur les monuments de Caen ( $\mathrm{XI}^{\mathrm{e}}-\mathrm{XII}^{\mathrm{e}}$ ss.)", Revue Archéologique de l'Ouest, 7, pp. 101-109.

Corzo, R. y Giles, F. (1980): "El abrigo de Laja Alta", Boletín del Museo de Cádiz, 2. "época, 1, pp. 19-36.

Dams, L. y Dams, M. (1984): "Ships and boats depicted in the prehistoric rock art of Southern Spain". En Blagg, T.; Jones, R. y Keay, S. (eds.): Papers in Iberian Archaeology. BAR Intern. Ser., 1. Oxford: Archaeopress, pp. 1-12.

EiroA, J. J. (1991-1992): "El barco de Bagil (una pintura rupestre histórica en Moratalla, Murcia)", Anales de Prehistoria y Arqueologia, 7-8, pp. 231-239.

García Serrano, J. A. (2012): Tiempo de graffiti. Los calabozos del Palacio Episcopal de Tarazona (ss. XVIII-XIX). Tarazona: Centro de Estudios Turolenses.

Gerrard, C. (2006): Paisaje y señorio: La casa conventual de Ambel. Arqueología, arquitectura e historia de las Órdenes militares del Temple y del Hospital. Zaragoza: Centro de Estudios Borjanos.

González Gonzalo, E.; Oliber Font, B. y Durán, M. (2000): "Los grafitos medievales del Castillo de Santueri (Felanitx, Mallorca)". En Actes XI Colloque International de Glyptographie de Palma de Majorque (1998). Mallorca: Centre International de Recherches Glyptographiques, pp. 229-249.

Guerrero, V. M. (2008a): "Barcos aborígenes en el Estrecho de Gibraltar". En VIII Jornadas de Historia de Ceuta (Ceuta, 2005). Ceuta: Instituto de Estudios Ceutíes, pp. 33-66.

Guerrero, V. M. (2008b): "Las naves de Kerné II. Navegando por el Atlántico durante la Protohistoria y la Antigüedad”. En González, R.; López, F. y Peña, V. (eds.): Los fenicios y el Atlántico. Madrid: Centro de Estudios Fenicios y Púnicos, pp. 69-142.

Guerrero, V. M. (2009): Prehistoria de la navegación. Origen y desarrollo de la arquitectura naval primigenia. BAR Intern. Ser., 1952. Oxford: Archaeopress.
Hernández Pérez, M.; Ferrer, P. y Català, E. (1986): "Arte rupestre en el Estret de les Aigües (Bellús-Xátiva, Valencia)", Lucentum, v, pp. 7-15.

Hernández Pérez, M.; Ferrer, P. y Català, E. (1988): Arte rupestre en Alicante. Catálogo. Valencia, 1988.

Jimeno, V. (2015): Arquitectura excavada y aprovechamiento de cuevas naturales en la Edad Media en la provincia de León. León: Univ. de León.

Konstam, A. (2015): Byzantine Warships vs. Arab Warships: 7-1 $1^{\text {th }}$ centuries. Oxford: Osprey Publishing Ltd.

Martín Goërg, M. F. y Martín Arrazola, C. (2011): "Escenas de pescas en la Laja Alta", Almoraima, 42, pp. 167-187.

Martín GoËrg, M. F. y Martín Arrazola, C. (2012): "Embarcaciones íberas en la Laja Alta. Consideraciones técnicas". Disponible en https://rodin.uca.es/ bitstream/handle/10498/14769/EMBARCACIONES\%20IBERAS\%20de\%20LAJA\%20ALTA03. pdf?sequence=1\&isAllowed=y; acceso 13/06/2018.

Martín Goërg, M. F.; PÁez, M. A. y Martín ArrazolA, C. (2016): "Lanchas de cuero en Laja Alta". Disponible en https://rodin.uca.es/xmlui/bitstream/ handle/10498/18470/LANCHAS\%20DE\%20 CUERO20EN20\%20LA\%20LAJA\%20ALTA.\%20 docx01.pdf;sequence $=1$; acceso 13-06-2018.

Martínez García, J. (2003): "Grabados rupestres en soportes megalíticos. Su influencia en los estudios de arte rupestre". En González Pérez, J. R. (coord.): Actes I Congrès Internacional de Gravats Rupestres $i$ Murals (Lleida, 1992). Lleida: IEI, pp. 71-88.

Mas, M. (2001): "Estructuras iconográficas e identificación de especies (secuencias iniciales y finales del arte postpaleolítico esquemático)", Quaderns de Prehistòria i Arqueologia de Castelló, 22, pp. 147-182.

Mas, M.; Jorge, A.; Gavilán, B.; Solís, M.; Parra, E. y PÉrez, P. P. (2013): "Minateda Rock Shelters (Albacete) and post-Palaeolithic art of the Mediterranean Basin in Spain: pigments, surfaces and patinas", Journal od Archaeological Science, 40, pp. 4635-4647.

Mateo, M. A. (1993): "Documentos para la historia moderna de Moratalla. Las pinturas rupestres de la cueva del Esquilo", Antigüedad y Cristianismo, x, pp. 593-608.

Morgado, A.; García-Alfonso, E.; García Moral, L. F.; Benavides, J. A.; Rodríguez-Tovar, F. y EsQuivel, J. A. (2018): "Embarcaciones prehistóricas y representaciones rupestres. Nuevos datos del abrigo de Laja Alta (Jimena de la Frontera, Cádiz)", Complutum, 29 (2), pp. 239-265. 
Moyano, J. (2018): “¿Embarcaciones del IV milenio a. C. en el Estrecho de Gibraltar? Reforzando el debate sobre las pinturas del abrigo de Laja Alta a partir de las nuevas propuestas cronológicas", Revista Atlántica-Mediterránea de Prehistoria y Arqueología Social, 20, pp. 27-51.

NaKas, Y. D. (2017): "Tracing the Development of Mediterranean Medieval Warships from the 11th to 15th". En Frielinghaus, H.; Schmidts, T. y TsaMAKDA, V. (eds.): Schiffe und ihr Kontext Darstellungen, Modelle, Bestandteile -von der Bronzezeit bis zum Ende des Byzantinischen Reiches, Internationales Kolloquium (Mainz, 2013). Mainz: vRGZ, pp. 185-197.

Ozcáriz, P. (2008): "Los grafitos del claustro de la catedral de Pamplona: dibujos destacados y torres medievales", Trabajos de Arqueología de Navarra, 20, pp. 285-310.

OzCáriz, P. (2011): “Estudio de los grafitos”. En Lazcano, M. R. (coord.): Santa María de Ujué. Pamplona: Fund. Conservación del Patrimonio Histórico de Navarra, pp. 170-181.

Pryor, J. y Jefrreys, E. (2006): The Age of the dromon. The Byzantine Navy ca. 500-1204. Leiden-Boston: Brill.

Retuerce, M. y Hervás, M. A. (2003): "Excavaciones arqueológicas en Calatrava la Vieja. Planteamientos y principales resultados". En Investigaciones Arqueológicas en Castilla-La Mancha 1996-2002. Colección Patrimonio Histórico Arqueológico, 18. Toledo: Junta de Comunidades de Castilla La Mancha, pp. 381-394.

Rey da Silva, A. (2014): "Nautical iconography from the Iberian Peninsula in Prehistory". En Tripati, S. (ed.): Maritime Contacts of the Past. Deciphering Connections amongst Communities. New Delhi: Delta Book World, pp. 368-401.
Rigaud, P. (1996): "Graffiti marins: abayye de Montmanjour". En Le graffito oreille des murs. Graffiti marins. Catálogo de la exposición Rivages de Méditerranée. Aix-en-Provence, pp. 18-29.

Royo, J. I. y Gómez Lecumberri, F. (2002): "Panorama general de los graffiti murales y grabados al aire libre medievales y postmedievales en Aragón”. En Los graffiti: un patrimonio inédito para el análisis de la Historia de las Mentalidades. Al-Qannis, 9. Teruel, pp. 146-149.

Ruiz Gálvez, M. (2005): "Representaciones de barcos en el arte rupestre: piratas y comerciantes en el tránsito de la Edad del Bronce a la Edad del Hierro", Mayurqa, 30, pp. 307-339.

SAssoon, H. (1993): "Los barcos pintados en el abrigo de Laja Alta". En I Jornadas del Seminario Permanente de Historia y Arqueología (Jimena de la Frontera, 1993). Algeciras, pp. 15-26.

Topper, U. (1975): "Felsbilder an der Südspitze Spaniens", Madrider Mitteilungen, 16, pp. 25-55.

Topper, U. y Topper, U. (1988): Arte Rupestre en la provincia de Cádiz. Cádiz: Diput. de Cádiz.

VÁzquez, I. (2015): "Iconografía náutica en el arte de las sociedades prehistóricas de la Península Ibérica. Certezas e incertidumbres". En Medina, M. A.; RoMERo, A.; Ruiz, R. y SANChidrián, J. L. (eds.): Sobre rocas y huesos: las sociedades prehistóricas y sus manifestaciones plásticas. Nerja: Univ. de Córdoba-Fund. Cueva de Nerja, pp. 300-317.

Viñas, R. y Sarriá, E. (1981): "Los grabados medievales del Racó Molero (Ares del Maestre, Castellón)", Cuadernos de Prehistoria y Arqueología Castellonense, 8, pp. 287-298.

vv. AA. (1986): Actas I Congreso de Arqueología Medieval Española. Zaragoza: Diput. General de Aragón. 